\title{
Climate Variability, Volcanic Forcing, and Last Millennium Hydroclimate Extremes
}

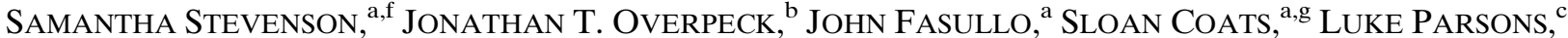 \\ Bette OtTo-Bliesner, ${ }^{\mathrm{a}}$ TOBy Ault, ${ }^{\mathrm{d}}$ GARRison LOOPE, ${ }^{\mathrm{c}}$ AND Julia COLE ${ }^{\mathrm{e}}$ \\ ${ }^{a}$ Climate and Global Dynamics Division, National Center for Atmospheric Research, Boulder, Colorado \\ ${ }^{\mathrm{b}}$ School for Environment and Sustainability, University of Michigan, Ann Arbor, Michigan \\ ${ }^{\mathrm{c}}$ Department of Geosciences, The University of Arizona, Tucson, Arizona \\ ${ }^{\mathrm{d}}$ Department of Earth and Atmospheric Science, Cornell University, Ithaca, New York \\ ${ }^{\mathrm{e}}$ Department of Earth and Environmental Sciences, University of Michigan, Ann Arbor, Michigan
}

(Manuscript received 14 June 2017, in final form 9 February 2018)

\begin{abstract}
Multidecadal hydroclimate variability has been expressed as "megadroughts" (dry periods more severe and prolonged than observed over the twentieth century) and corresponding "megapluvial" wet periods in many regions around the world. The risk of such events is strongly affected by modes of coupled atmosphere-ocean variability and by external impacts on climate. Accurately assessing the mechanisms for these interactions is difficult, since it requires large ensembles of millennial simulations as well as long proxy time series. Here, the Community Earth System Model (CESM) Last Millennium Ensemble is used to examine statistical associations among megaevents, coupled climate modes, and forcing from major volcanic eruptions. El NiñoSouthern Oscillation (ENSO) strongly affects hydroclimate extremes: larger ENSO amplitude reduces megadrought risk and persistence in the southwestern United States, the Sahel, monsoon Asia, and Australia, with corresponding increases in Mexico and the Amazon. The Atlantic multidecadal oscillation (AMO) also alters megadrought risk, primarily in the Caribbean and the Amazon. Volcanic influences are felt primarily through enhancing AMO amplitude, as well as alterations in the structure of both ENSO and AMO teleconnections, which lead to differing manifestations of megadrought. These results indicate that characterizing hydroclimate variability requires an improved understanding of both volcanic climate impacts and variations in $\mathrm{ENSO} / \mathrm{AMO}$ teleconnections.
\end{abstract}

\section{Introduction}

Droughts lasting decades or longer pose a significant challenge for resource managers, threatening water and food security as well as human health (i.e., Acuna-Soto et al. 2002). These "megadroughts" have been thoroughly documented in the paleoclimate record, and paleoclimate evidence suggests that they were likely more prolonged than twentieth-century droughts, with potentially higher severity as well (Stine 1994; Cook et al. 2004; Woodhouse and Overpeck 1998; Cook et al. 2016). Thus, understanding

\footnotetext{
${ }^{\mathrm{f}}$ Current affiliation: Bren School of Environmental Science and Management, University of California, Santa Barbara, Santa Barbara, California.

${ }^{\mathrm{g}}$ Current affiliation: Woods Hole Oceanographic Institution, Woods Hole, Massachusetts.
}

Corresponding author: Samantha Stevenson, stevenson@bren. ucsb.edu the causes and expected variations of megadroughts is crucial (Coats and Mankin 2016), particularly since projected warming and drying trends are expected to intensify megadroughts in many regions (Cayan et al. 2010; Seager et al. 2013; Cook et al. 2015; Ault et al. 2016).

Comparatively little work has focused on sustained wet extremes, yet the impact of such "megapluvials" is equally relevant (Routson et al. 2016). The early twentieth century was anomalously wet in the U.S. Southwest, with implications for water management via the Colorado River Compact, and increasing temperature stresses in the region are contributing to these wet periods becoming less frequent (Griffin and Anchukaitis 2014; Woodhouse et al. 2016; Udall and Overpeck 2017). Additionally, changes to the behavior of megapluvials may not necessarily correspond precisely with changes in megadrought; understanding both types of "megaevents" is needed to fully characterize the overall risk of extremes.

Coupled atmosphere-ocean variability has welldocumented influences on hydroclimate. El Niño-Southern 
Oscillation (ENSO), in particular, has been implicated in causing megadroughts over the past millennium by both model- and proxy-based studies, with persistent La Niña conditions being associated with megadrought in the North American Southwest/Mexico (Graham et al. 1994; Cole and Cook 1998; Cayan et al. 1999; McCabe et al. 2004; Herweijer et al. 2007; Seager et al. 2008; Conroy et al. 2009a) and persistent El Niño associated with Australian and Southeast Asian megadrought (Power et al. 2006; Ummenhofer et al. 2009). Links with the Pacific decadal oscillation (PDO) and megadrought have also been documented (Coats et al. 2016a), although some questions remain as to the effects from interrelationships between ENSO and the PDO (Newman et al. 2016) and to the stationarity of PDO teleconnections (McAfee 2014). The Atlantic multidecadal oscillation (AMO) is also strongly linked with persistent drought, particularly in the United States (Oglesby et al. 2012) and in the Amazon basin (Zeng et al. 2008). Interactions between teleconnections associated with both modes are thought to substantially affect hydroclimate conditions on these time scales in the southwestern United States (Coats et al. 2016a,b; Seager and Ting 2017). However, the impact of coupled modes is not always straightforward: previous work has shown substantial unforced variability in regional ENSO/AMO teleconnections (Cole and Cook 1998; Cole et al. 2002; Conroy et al. 2009a; Coats et al. 2013, 2015b), and atmosphere-land interactions have been shown to be capable of generating multidecadal hydroclimate variability, even in the absence of coupling with the ocean (Stevenson et al. 2015; Taschetto et al. 2016).

The role of external forcing in generating past megadroughts is also a topic of debate. Reconstructions for the western United States indicate that the most severe megadroughts occurred during the AD 900-1300 period, an epoch known as the Medieval Climate Anomaly, which was characterized by warm global surface temperature, high solar irradiance, and low volcanic activity (Graham et al. 2007; Conroy et al. 2009b; Graham et al. 2011; Coats et al. 2016a). Likewise, strong volcanic eruptions are known to drastically influence hydroclimate (Anchukaitis et al. 2010; Li et al. 2013; Maher et al. 2015; Colose et al. 2016; Stevenson et al. 2016, 2017), but whether these eruptions impact the overall multicentennial statistics of megadrought remains unknown.

Climate models provide a useful framework for diagnosing the mechanisms responsible for megaevent generation, despite some caveats related to the role of structural biases and issues with the amplitude of low-frequency variability (Gleckler et al. 2008; Ault et al. 2013; Bellenger et al. 2014; Coats et al. 2015a). However, the long time scales and small event sample sizes involved in these studies require ensembles of millennial-scale simulations, which are not typically performed by modeling centers due to their high
TABLE 1. Simulations in the LME analyzed for the present study. A full description of model configurations for each subensemble can be found in Otto-Bliesner et al. (2016).

\begin{tabular}{lc}
\hline \hline \multicolumn{1}{c}{ Ensemble } & No. simulations \\
\hline Full forcing & 13 \\
Greenhouse gas only & 3 \\
Land use-land cover only & 3 \\
Solar only & 4 \\
Orbital only & 3 \\
Volcanic only & 5 \\
\hline
\end{tabular}

computational cost. The present study uses the Community Earth System Model (CESM) Last Millennium Ensemble (LME; Otto-Bliesner et al. 2016), an ensemble developed to provide a unique community resource capable of overcoming last millennium signal-to-noise issues. The LME contains over 30 realizations of the 850-2005 period: to date, 13 simulations have been run with all major natural and anthropogenic influences (Schmidt et al. 2011), and smaller suites of single-forcing experiments are also included to allow the investigation of individual external forcings.

We recognize that model biases in simulating decadal to multidecadal hydroclimate may well affect the simulated influences of internal climate variability and external forcing on megadrought (Ault et al. 2013). An increase in the extent of low-frequency hydroclimate variability would tend to interfere with the teleconnected influence of modes such as ENSO and the AMO; likewise, an overestimate of ENSO/AMO amplitude might create a tendency for multidecadal hydroclimate variations to be overly damped (or potentially inappropriately magnified). At present, however, it is not possible to conclusively determine the role of model biases, owing to the lack of relevant observational and paleoclimate validation information (Parsons et al. 2017). The goal of the present investigation is to provide statistically robust quantification of megaevent sensitivity to both coupled climate variability and external forcing in a physically consistent framework, which can guide future investigations on model-proxy comparisons on this topic.

\section{Definitions, study regions, and model evaluation}

Here, we analyze all LME members covering the entire 850-2005 period. The construction of the LME is described in detail in Otto-Bliesner et al. (2016); the ensemble consists of several distinct subensembles, which include various external forcing factors. These are greenhouse gas emissions, solar irradiance changes, orbital forcing, volcanic eruptions, land use-land cover changes, ozone and anthropogenic aerosol emissions, and all of these factors combined (the so-called "full forcing" runs). Simulations used in this study are summarized in Table 1 . Note that no 

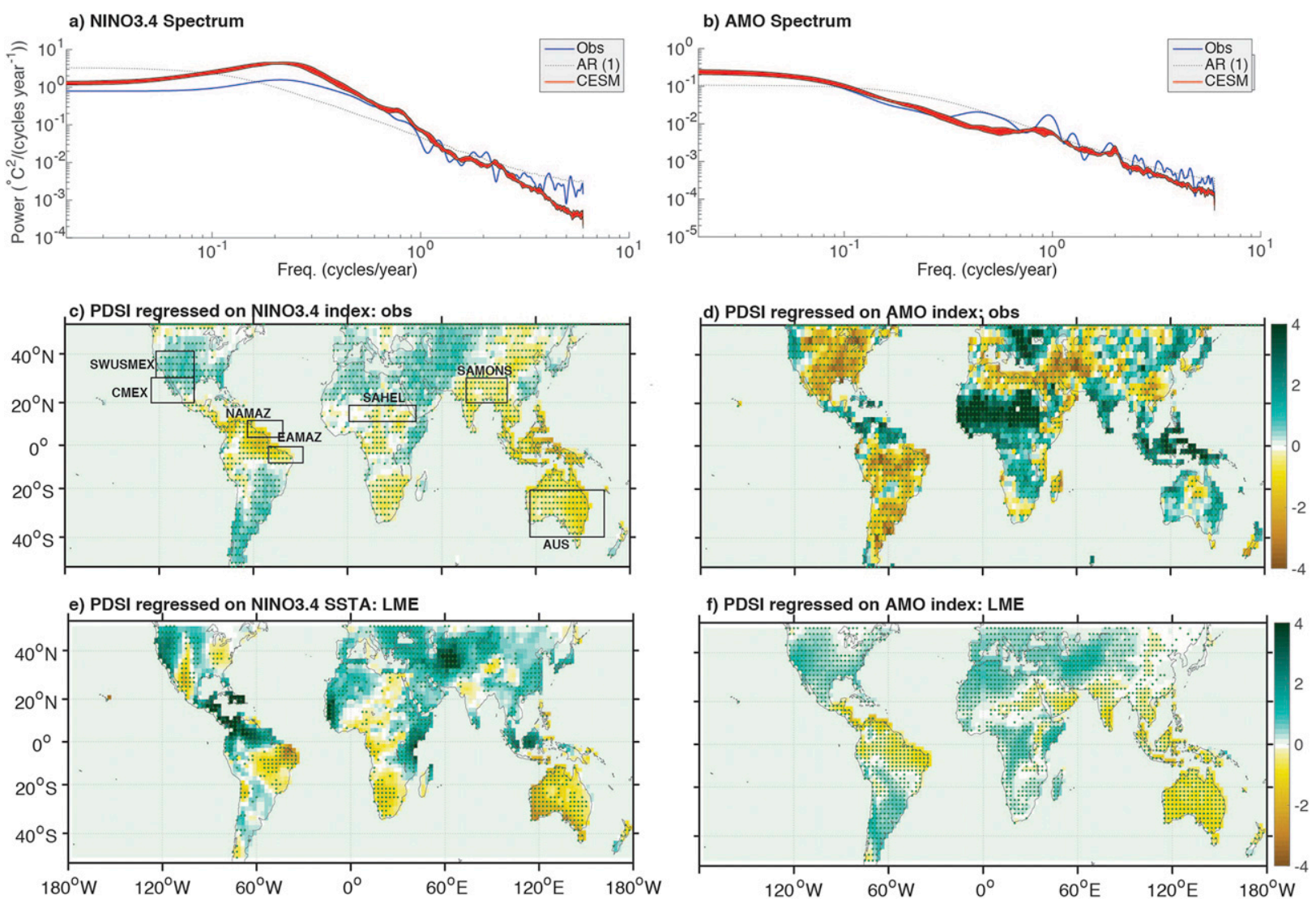

FIG. 1. Representation of the dominant climate modes in CESM, compared with observations: (a) ENSO (the Niño-3.4 index) and (b) the AMO index. Spectra are computed using the method of Welch, with window length of 120 months, overlapping by $40 \%$. Observational time series in (a),(b) are derived from the Climate Variability Diagnostics Package (Phillips et al. 2014), which relies on the HadISST product (Rayner et al. 2003). A dotted line indicates the null hypothesis: an AR(1) model fitted to the monthly observational time series. Values above this line are significant at or above 90\%. (c)-(f): Regression of PDSI (Dai et al. 2004) on Niño-3.4 and AMO indices for observations [(c),(d) ERSST.v4; Huang et al. (2015); and (e),(f) the LME] for the 1950-2000 period. LME results represent the mean regression pattern averaged across the 13 full-forcing simulations. Stippling in (c),(d) indicates that regression coefficients are significantly different from zero and in (e),(f) that regression coefficients are significantly different from zero in at least two-thirds of ensemble members.

detrending has been applied to the data in the subsequent analyses, and as such, some anthropogenic impacts may be present during the 1850-2005 period; however, we do not expect that this will greatly affect the results, as analyses carried out over 850-1850 show no substantial differences to the results presented here (not pictured).

The overall performance of the present configuration of CESM has been evaluated extensively elsewhere (Otto-Bliesner et al. 2016; Stevenson et al. 2016, 2017). For reference, we present spectra for the Niño-3.4 [sea surface temperature (SST) averaged over $5^{\circ} \mathrm{S}-5^{\circ} \mathrm{N}$, $\left.120^{\circ}-170^{\circ} \mathrm{W}\right]$ and AMO indices in Fig. 1. The latter is defined using monthly index time series derived from North Atlantic $\left(0^{\circ}-60^{\circ} \mathrm{N}, 80^{\circ} \mathrm{W}-0^{\circ}\right)$ SST anomalies minus global $\left(60^{\circ} \mathrm{S}-60^{\circ} \mathrm{N}\right) \mathrm{SST}$ anomalies (Trenberth and Shea 2006), and observational SST is taken from the HadISST product (Rayner et al. 2003). As previously noted (Stevenson et al. 2016, 2017; Parsons et al. 2017), tropical Pacific variability is too strong in CESM by nearly a factor of 2 in amplitude at decadal time scales (Fig. 1a). The AMO appears to be more faithfully represented (Fig. 1b), although the low-frequency nature of this mode, as well as known issues with observational data quality in the early twentieth century (Deser et al. 2010), make this evaluation less certain. CESM captures the ENSO teleconnection well in most locations, as demonstrated using regression maps of the monthly Palmer drought severity index (PDSI; Palmer 1965) on the Niño-3.4 index (Figs. 1c,e). In Figs. 1c and 1e, the PDSI dataset of Dai et al. (2004) and the NOAA ERSST, version 4 (ERSST.v4; Huang et al. 2015), constitute the observational datasets for regression.

Some exceptions to this rule do exist, most notably in Africa, where there are known issues with the 
TABLE 2. Study regions defined for examination of modal conditions during megadrought and megapluvial events.

\begin{tabular}{lcc}
\hline \hline \multicolumn{1}{c}{ Region } & Lat limits & Lon limits \\
\hline SWUSMEX & $30^{\circ}-40^{\circ} \mathrm{N}$ & $95^{\circ}-115^{\circ} \mathrm{W}$ \\
CMEX & $20^{\circ}-30^{\circ} \mathrm{N}$ & $95^{\circ}-120^{\circ} \mathrm{W}$ \\
AUS & $20^{\circ}-40^{\circ} \mathrm{S}$ & $120^{\circ}-160^{\circ} \mathrm{E}$ \\
SAMONS & $20^{\circ}-30^{\circ} \mathrm{N}$ & $75^{\circ}-105^{\circ} \mathrm{E}$ \\
NAMAZ & $5^{\circ}-10^{\circ} \mathrm{N}$ & $40^{\circ}-60^{\circ} \mathrm{W}$ \\
EAMAZ & $0^{\circ}-10^{\circ} \mathrm{S}$ & $30^{\circ}-50^{\circ} \mathrm{W}$ \\
SAHEL & $10^{\circ}-20^{\circ} \mathrm{N}$ & $0^{\circ}-40^{\circ} \mathrm{E}$ \\
\hline
\end{tabular}

CESM-ENSO teleconnection patterns (Fasullo et al. 2016; Fasullo and Nerem 2016). The teleconnection structure in CESM is more reliable for ENSO than for the AMO (Figs. 1c,e vs 1d,f). This may relate to known problems with the spatial structure of the AMO in CESM and other climate models (Seager 2015; Kushnir et al. 2010; Ting et al. 2011): for the AMO, the regression disagrees with CESM in some locations (e.g., in portions of Australia and central Africa).

For portions of this analysis (see section 3), we compute megadrought statistics in regions of particular climatic and socioeconomic relevance. The precise extent of these regions has been estimated based on our assessments of locations where ENSO/AMO/volcanic influences tend to be strong. The first study region includes the southwestern United States and a small portion of Mexico (SWUSMEX); in addition to its large and growing population, this region has been the focus of extensive megadrought research. We have also considered central Mexico (CMEX) separately, as aspects of its megadrought variability are quite distinct. Australia (AUS) and Southeast Asia (SAMONS) have been included due to their strong ENSO teleconnections, as has the Amazon basin; here, we have split the latter region into northern (NAMAZ) and eastern (EAMAZ) domains, which the following sections will demonstrate behave quite differently. The final study region is the Sahel (SAHEL), which also experiences strong ENSO/ AMO teleconnections and is home to populations extremely vulnerable to drought and famine risks during such extremes (Held et al. 2005; Shanahan et al. 2009; Villamayor and Mohino 2015; Gautier et al. 2016). The latitude-longitude boundaries of all regions are listed in Table 2.

We have generated the PDSI data based on output from all LME members, using the Penman-Monteith formulation for potential evapotranspiration (Jacobi et al. 2013), as was done for previous LME analyses (Stevenson et al. 2016). The PDSI is used as the preferred drought metric throughout this analysis; although there are known issues with the PDSI (Alley 1984), it is unavoidable here, as the tree-ring records calibrated to
JJA PDSI are the only available source of validation data of sufficient temporal extent.

From both CESM-computed and tree-ring-derived PDSI data, we compute regionally averaged time series from which megaevents are identified following the procedure of Ault et al. (2013). The PDSI time series is standardized using the mean and standard deviation $\sigma$ over 850-1849 for each LME ensemble member to create " $Z$ scores," and running 15 -yr averages of these values are then calculated. Megadrought and megapluvial events are defined as epochs in which the $15-\mathrm{yr}$ running mean falls below $-0.5 \sigma$ or above $+0.5 \sigma$, and their persistence is then the time between the associated zero-point crossings. The risk associated with megadrought is the proportion of time spent in megadrought conditions. We include both persistence and risk in the present analysis, as both provide useful insights: as with persistence, the overall risk is an important metric for management purposes, and looking at megadrought and megapluvial persistences individually then indicates the degree to which risk is affected by symmetric changes in hydroclimate variability versus changes in one or the other sign of extreme. It should also be noted that the choice of averaging period for the running-mean PDSI is an arbitrary one; other periods were examined as well. We find that for time scales of roughly $15-35 \mathrm{yr}$ [the "decadal-multidecadal" range of Ault et al. (2013)], the major findings of the analysis do not change.

Although CESM simulates hydroclimate well overall (Stevenson et al. 2017), there are some indications that megadrought behavior in this model may not correspond with observations (Ault et al. 2013; Stevenson et al. 2015; Otto-Bliesner et al. 2016; Cook et al. 2016; Coats et al. 2015b). Here, we validate CESM megaevent properties against several proxy data sources: gridded hydroclimate data from the North American Drought Atlas (NADA; Cook et al. 2004), the Mexican Drought Atlas (Stahle et al. 2016), the Monsoon Asia Drought Atlas (MADA; Cook et al. 2010), and the Australia-New Zealand Drought Atlas (ANZDA; Palmer et al. 2015). Overall model performance is good, with overlapping interquartile ranges for megadrought persistences in the LME versus reconstructions, albeit with a slight tendency for megadrought persistence to be overestimated in the LME (Fig. 2). The persistence of megapluvials in the LME is shorter, compared with reconstructions in some regions (SWUSMEX, CMEX, and AUS), and longer in others (SAMONS). These comparisons do not appear to be consistently related to the LME's ability to capture observed event occurrence frequencies: the LME shows too few megapluvials in SWUSMEX and CMEX and too many in AUS. However, overall, the LME appears broadly consistent with 

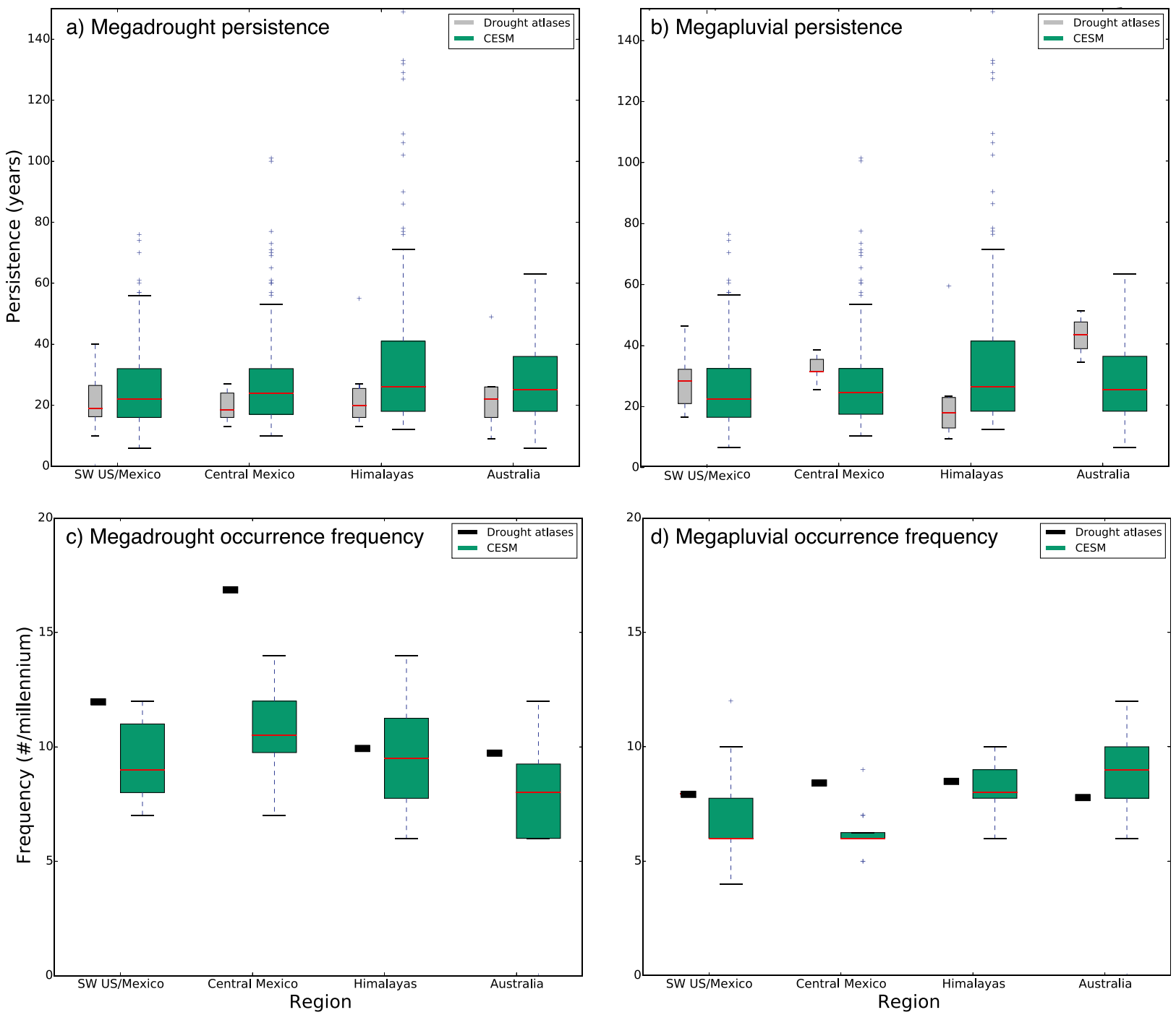

FIG. 2. The representation of megadrought events in the CESM (regionally averaged) as compared with drought atlases: NADA (southwestern United States-Mexico), the Mexican Drought Atlas (central Mexico), MADA (Himalayas), and ANZDA (Australia). Green boxes indicate data derived from the CESM LME full-forcing simulations and gray boxes data from drought atlases. Red horizontal lines show the median megadrought persistence across the CESM full-forcing simulations, the width of the box is the interquartile range, whiskers are the 5th and 95th percentiles, and blue crosses outlier points. Persistence of (a) megadroughts and (b) megapluvials with (c),(d) the corresponding occurrence frequencies. (c),(d) Black squares indicate the mean megadrought occurrence frequencies derived from each of the atlas products.

the drought atlases in terms of megaevent representation in these regions. This is particularly true given the potential for uncertainties in tree-ring reconstructions, and possible seasonal biases in the tree-ring data (St. George et al. 2010), to create errors in megadrought properties estimated from the drought atlases.

\section{Internal variability and hydroclimate extremes}

Applying the approach discussed in section 2 to all model grid points allows the creation of a spatially complete picture of hydroclimate variability. Figure $3 \mathrm{~b}$ shows the resulting map of ensemble-mean megadrought persistences, which behave as one would intuitively expect: megadroughts tend to be longer in more arid regions and shorter in wetter locations. There are a few exceptions to this rule, most notably in the central Amazon and the SAMONS region, where relatively wet conditions coexist with high megadrought persistences. This may relate to long-term memory associated with vegetation and snowpack in the Amazon and Himalayas, respectively. Interestingly, the overall variance in PDSI 

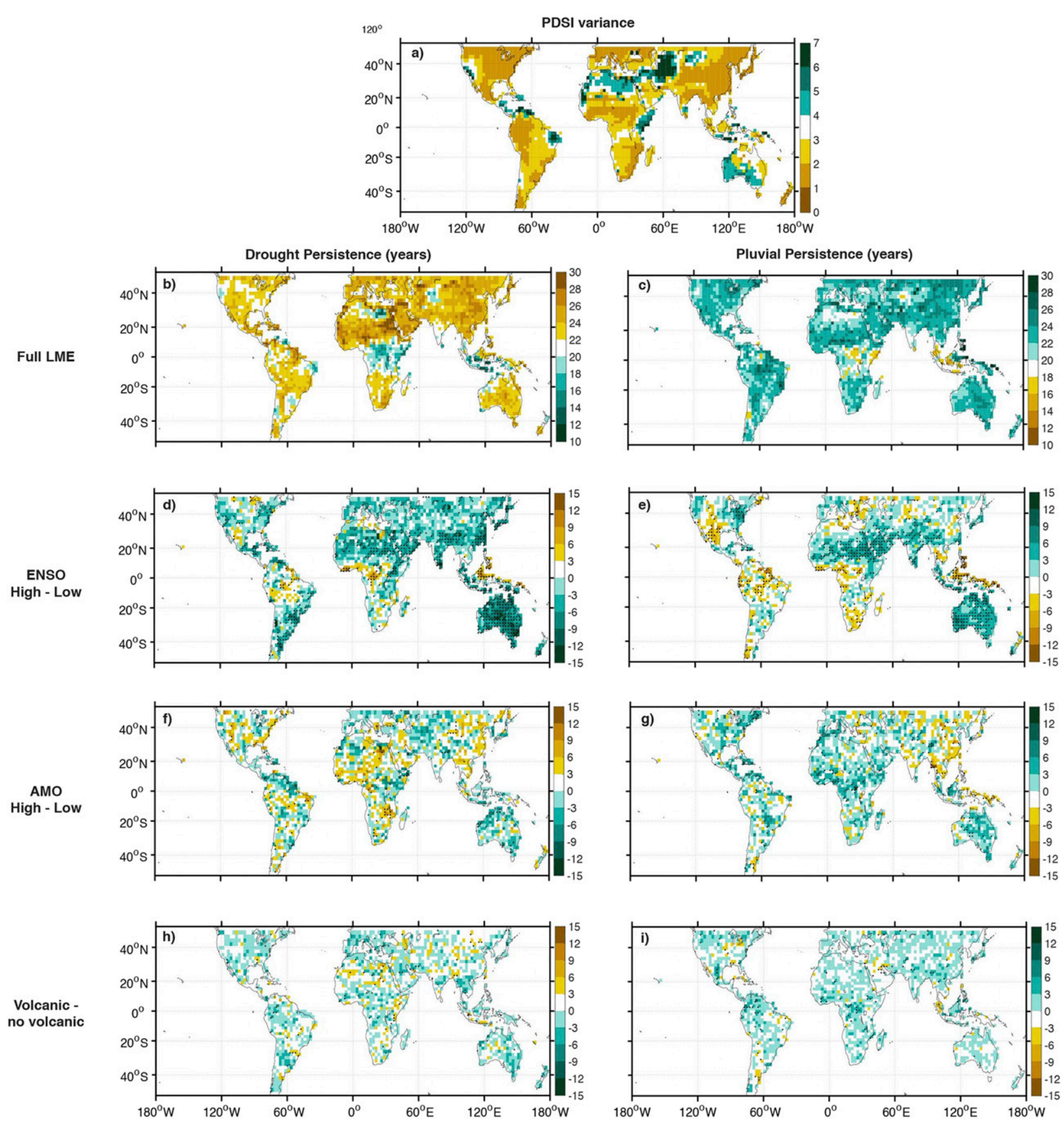

FIG. 3. Effects of ENSO, the AMO, and volcanic forcing on the persistence of megadrought and megapluvial periods in the full LME (units of yr), including all full-forcing and single-forcing members, over the 850-1849 period. (a) Variance of PDSI in the LME. (b),(c) Mean megadrought and megapluvial persistence across all LME simulations, respectively. (d),(e) Differences between megadroughtmegapluvial persistences in high vs low ENSO epochs, respectively. (f),(g) As in (d),(e), but for the AMO. (h),(i) Difference in megadrought and megapluvial persistences between LME simulations with and without the inclusion of volcanic forcing, respectively. Stippling indicates locations where differences are significant at the $90 \%$ level, as measured using a Wilcoxon rank-sum test.

(Fig. 3a) does not show a clear relationship with megaevent persistence in most locations, with a few exceptions for high-variance regions (e.g., the low event persistences along the U.S. West Coast, northern Africa, and western Australia).
We next investigate the influence of ENSO and the AMO on the persistence of megaevents, as well as megadrought risk. We use 200-yr nonoverlapping subintervals of PDSI and modal index time series to calculate the properties of megadroughts and megapluvials 
a) Low-ENSO Epochs

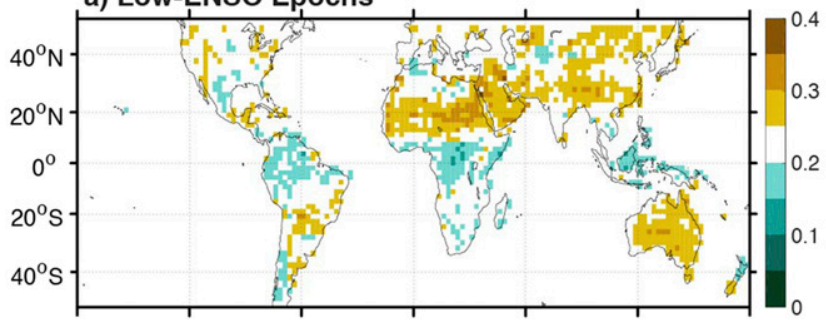

c) High - Low AMO

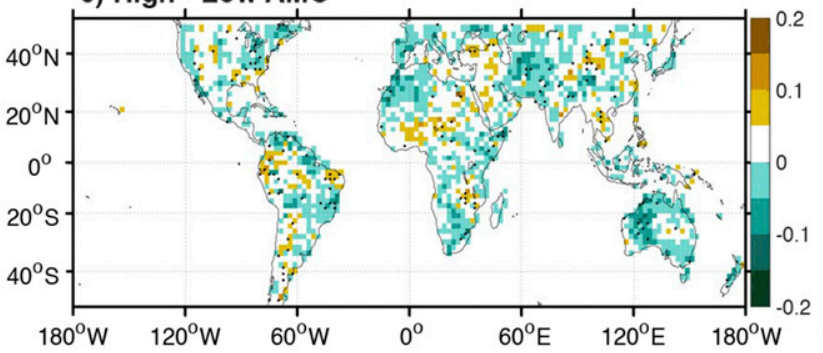

b) High - Low ENSO

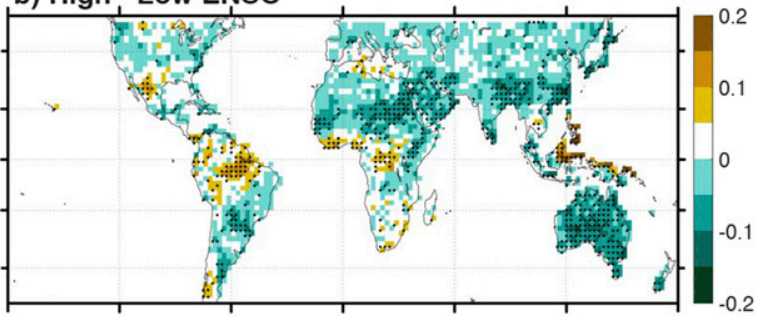

d) Volcanic - no volcanic

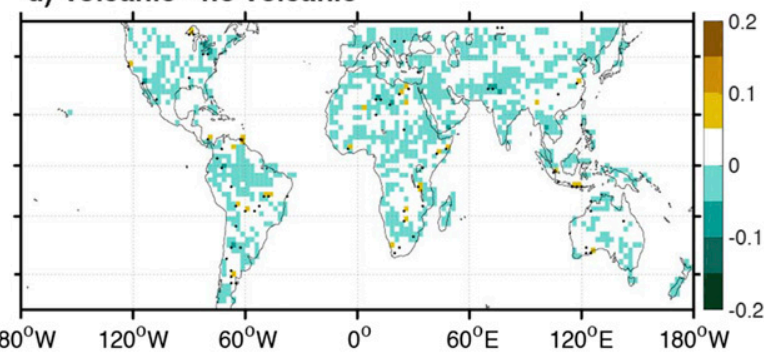

FIG. 4. (a) Anomalies in megadrought risk during periods of low ENSO variance. (b),(c) Effects of ENSO and the AMO on the overall risk of megadrought in the full set of LME simulations over the 850-1849 period, respectively. (d) As in (a),(b), but for the effects of volcanic forcing. Stippling indicates locations where differences are significant at the $90 \%$ level, as measured using a Wilcoxon rank-sum test.

and ENSO-AMO amplitude, creating a set of 5 times (number of runs) epochal values for each. The effects of $\mathrm{ENSO} / \mathrm{AMO}$ are then estimated as the changes in persistence or risk associated with differencing epochs of "high" (above the 60th percentile) and "low" (below the 40th percentile) variance in each mode of variability. In this and other cases, the significance of differences is evaluated by applying the Wilcoxon rank-sum test to the set of all events at each grid point. The use of a nonparametric test allows us to avoid assumptions regarding the underlying probability distribution function (PDF) of event persistences/risk.

Figures $3 \mathrm{~d}-\mathrm{g}$ show that both ENSO and the AMO influence megaevent persistence in many locations: high ENSO variance leads to shorter megadroughts and longer megapluvials in the SAHEL, AUS, and SAMONS regions. In contrast, high ENSO variance lengthens megadroughts and shortens megapluvials in CMEX and EAMAZ (Figs. 3d,e). Interestingly, the simulated ENSO influence in the southwestern United States is relatively small; megadroughts tend to lengthen and megapluvials to shorten somewhat, but CMEX shows much larger changes in both megadrought and megapluvial events due to ENSO. Figures $3 \mathrm{f}$ and $3 \mathrm{~g}$ show that the AMO's effects are weaker than ENSO's in many regions. However, high AMO variance lengthens SWUSMEX megadrought and shortens megadrought in NAMAZ. Megapluvials are not as strongly influenced by the AMO, indicating that AMO influences on hydroclimate are less symmetric with respect to the sign of the anomaly than ENSO impacts.
Changes to ENSO and the AMO also alter the overall risk of megadrought as defined in section 2, which is depicted in Fig. 4. Stronger ENSO variability is tied to risk reductions in AUS, SAHEL, and SAMONS: this results from changes in both megadrought and megapluvial lengths. In all three regions, epochs of stronger ENSO variance are associated with shorter megadrought and longer megapluvial events, which together account for the reduction in the proportion of time spent in megadrought conditions. However, the risk increases in CMEX; based on Fig. 3, this seems to relate to reduced persistence of megapluvial periods. The changes to megadrought risk due to AMO variability are much weaker (Fig. 4c); only in the northernmost Amazon and portions of the Middle East do these changes become statistically significant. These influences are summarized for all study regions in Table 3.

To understand the mechanisms for the ENSO- and AMO-driven effects in Fig. 3, it is necessary to examine how changes in ENSO and AMO variance lead to 1) shifts in mean conditions throughout the tropics and midlatitudes (i.e., by rectification of high vs low ENSOAMO teleconnection patterns into the mean state) and 2) changes in hydroclimate statistics due to changing the frequency and/or magnitude of positive or negative extremes. The net effect of changing ENSO-AMO variance is likely some combination of both. We also note that it is possible for interactions between ENSO and the AMO to affect the occurrence of megadrought; this has been shown in simulations and the proxy record in the past (Feng et al. 2008; Oglesby et al. 2012; Coats et al. 
TABLE 3. Effects of ENSO and the AMO on megadroughts and megapluvials in study regions. The plus sign indicates lengthening or increased risk for epochs with greater variance in these modes, and the minus sign indicates shortening or decreased risk. N/A indicates minimal change.

\begin{tabular}{llccc}
\hline \hline Mode & \multicolumn{1}{c}{ Region } & Megadrought length & Megapluvial length & Drought risk \\
\hline ENSO & SWUSMEX & - & N/A & - \\
ENSO & CMEX & + & - & + \\
ENSO & NAMAZ & - & N/A & N/A \\
ENSO & EAMAZ & - & + & + \\
ENSO & SAMONS & - & + & - \\
ENSO & SAHEL & - & N/A & - \\
ENSO & AUS & + & N/A & N/A \\
AMO & SWUSMEX & N/A & N/A & N/A \\
AMO & CMEX & - & N/A & - \\
AMO & NAMAZ & N/A & N/A \\
AMO & EAMAZ & + & + \\
AMO & SAMONS & N/A & N/A \\
AMO & SAHEL & - & N/A \\
AMO & AUS & & - \\
\hline
\end{tabular}

2016b). The fact that the AMO operates on much longer time scales than ENSO may also have dynamically interesting consequences, as ENSO variability within a given AMO regime can lead to differing consequences for hydroclimate, which may manifest as nonlinear interactions between the two modes. These possibilities are not explicitly investigated here due to length constraints, but remain as an interesting topic for future work.

The first possibility is investigated by compositing mean temperature, precipitation, sea level pressure (SLP), and 0-30-cm soil moisture between high- and low-variance epochs, shown in Fig. 5. When ENSO variance increases, a dipolar structure is present in the surface air temperature anomaly in the equatorial Pacific, with cold anomalies extending from the midlatitudes to the warm pool (Fig. 5a). This bears a qualitative resemblance to the El Niño-La Niña difference in CESM (not pictured) and thus could potentially be considered to result from the larger relative increase in El Niño versus La Niña during epochs of strong ENSO variance. However, the patterns in Fig. 5a are not identical with the teleconnection pattern associated with El Niño; this is particularly apparent in Australia, where cooling and wetting occur rather than the canonical El Niño-driven warming and drying. To fully understand this pattern likely requires examining other aspects of ENSO dynamics, including variations in El Niño
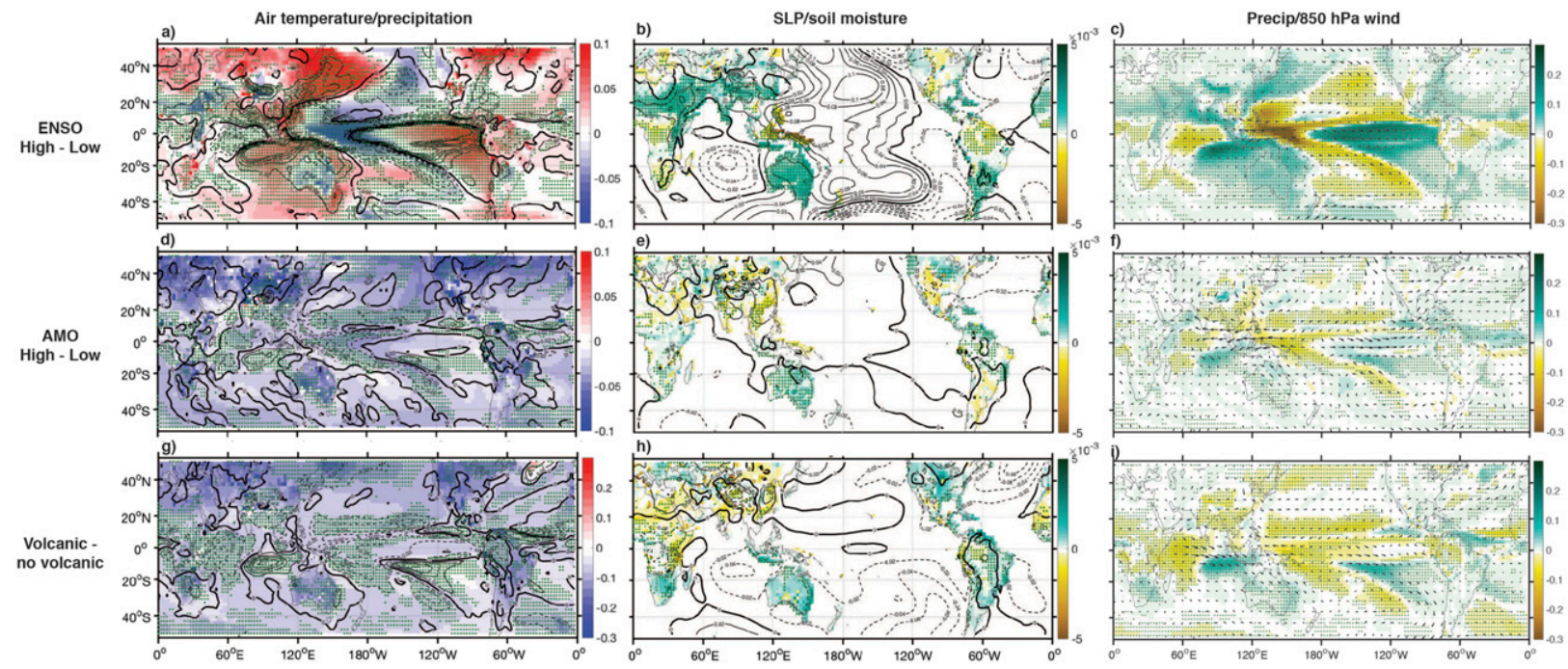

FIG. 5. (a),(d) Differences in surface air temperature $\left({ }^{\circ} \mathrm{C}\right.$; colors) and precipitation ( $\mathrm{mm} \mathrm{day}^{-1}$; contours) between high and low ENSOand AMO-variance epochs, respectively. (b),(e): As in (a),(d), but for 0-30-cm soil moisture ( $\mathrm{mm}^{3} \mathrm{~mm}^{-3}$; colors) and SLP (hPa; contours). (c),(f): As in (a),(d), but for precipitation ( $\mathrm{mm} \mathrm{day}^{-1}$; colors) and 850-hPa wind ( $\mathrm{m} \mathrm{s}^{-1}$; arrows). (g)-(i) As in (a)-(c), but for sets of LME simulations with and without the influence of volcanic forcing. Stippling indicates locations where (a),(d),(g) air temperature, (b),(e),(h) soil moisture, or (c),(f),(i) precipitation differences are significant at the $90 \%$ level, as measured using a Wilcoxon rank-sum test. 
"flavors" or the frequency of El Niño versus La Niña events, and potentially also decadal to multidecadal modes, such as the interdecadal Pacific oscillation (IPO).

The mean changes in Figs. 5a-c are consistent with megaevent persistence changes in many regions. For instance, the longer megadroughts and shorter megapluvials in Mexico during high ENSO variance epochs are influenced by the shift toward warmer and drier conditions, due to the shifting of the Bermuda highwarming North Atlantic, which suppresses moisture flow through the Gulf of Mexico (Fig. 5b). In the Amazon, high ENSO epochs also experience mean warming and drying, along with longer megadrought and shorter megapluvial events. Mean shifts appear consistent with megaevent changes in other study regions as well: in the southwestern United States, cooler and wetter conditions arise from high ENSO variance, a result of the enhanced surface high near $30^{\circ} \mathrm{N}$ and associated enhancement of the Aleutian low, which drives onshore flow in the western United States (Figs. 5b,c).

Changes to mean conditions as a function of AMO variance are shown in Figs. 5d-f. These changes differ dramatically from Figs. 5a to 5c; global cooling occurs during high AMO epochs, with the largest temperature anomalies over land. As will be demonstrated in section 4 , these mean changes are largely due to the presence of volcanic forcing, which both enhances AMO variability and cools the mean climate. However, the associated mean hydroclimate changes are less uniform, with regions of both wetting and drying apparent in Fig. 5e. Regions experiencing drying tend to be dominated by reductions in precipitation, in contrast to the ENSO impacts of Figs. 5a-c, which contain both temperatureand precipitation-driven components.

The changes to megaevent persistences due to AMO variance are generally less significant than their ENSOdriven counterparts, but in some locations do appear related to mean-state shifts during high AMO variance epochs (see Figs. 5e, 3f). This is particularly apparent in SWUSMEX, CMEX, NAMAZ, and AUS: in the first two, mean soil moisture decreases, while megadrought persistence increases in high AMO variance epochs. In the latter two regions, the pattern is reversed. Interestingly, however, the AMO-driven changes to megadroughts and megapluvials are much less symmetric than was the case for ENSO. For instance, in Mexico, changes to megadrought persistence are stronger than megapluvials: it is possible that in high AMO epochs, the mean drying in this region tends to favor changes to megadrought persistence by enabling already-drier soils to remain below the megadrought threshold for longer periods of time. Asymmetric behavior is also seen in NAMAZ, where very little AMO-driven change in megapluvial persistence takes place: here, high AMO epochs tend to exhibit wetter mean conditions, and therefore, perhaps, mean cooling preferentially influences megapluvials by extending events that might otherwise have terminated due to evaporative demand. This increased asymmetry may potentially arise due to the much longer time scale of AMO variability relative to ENSO, which allows existing anomalies more time to grow.

We next investigate the second hypothesis for the ENSO-AMO impact on megaevent persistences: an enhanced alternation between wet and dry anomalies as a result of modal teleconnections. This is illustrated for ENSO in Fig. 6, which shows the state of the Niño-3.4 index at the beginning and end of megadrought periods. In most regions, megadrought initiation/termination are clearly associated with ENSO, whereas the associations are less clear for SAHEL. This suggests that in most of our study regions, the role of variance changes is likely an increased alternation between El Niño and La Niña phases, rather than a strengthening of the events themselves. When similar PDFs are constructed for the phase of the AMO during megadrought start and end years, a much weaker relationship is seen than for ENSO (Fig. 7), with EAMAZ exhibiting the only substantial, statistically significant AMO index shift. This is likely because the dominant time scale of AMO variability is longer than the 15-yr averaging time scale for megadrought, making it much more difficult for "switching", between warm and cold AMO phases to be captured in megadrought initiation and termination (though we note that the same behavior is observed when a 35-yr running mean is used for megaevent computation; not pictured). This lack of systematic associations with the AMO index suggests that the AMO impact on megadrought risk may primarily result from a change in mean conditions rather than direct impacts from discrete AMO events.

\section{Influences from volcanic forcing}

The next question is to what extent externally forced changes in climate can modulate the results of section 3. Although the design of the LME permits the examination of individual forcing factors, here we focus strictly on the influence of volcanic eruptions, as it is by far the largest influence on last millennium climate when examined in a radiative-imbalance context (Otto-Bliesner et al. 2016). We estimate the impacts of volcanism on megaevents using subsets of LME simulations with and without volcanic forcing; these are shown in Figs. $3 \mathrm{~h}$ and $3 \mathrm{i}$ for megadrought and megapluvial persistence and in Fig. 4d for megadrought risk. 

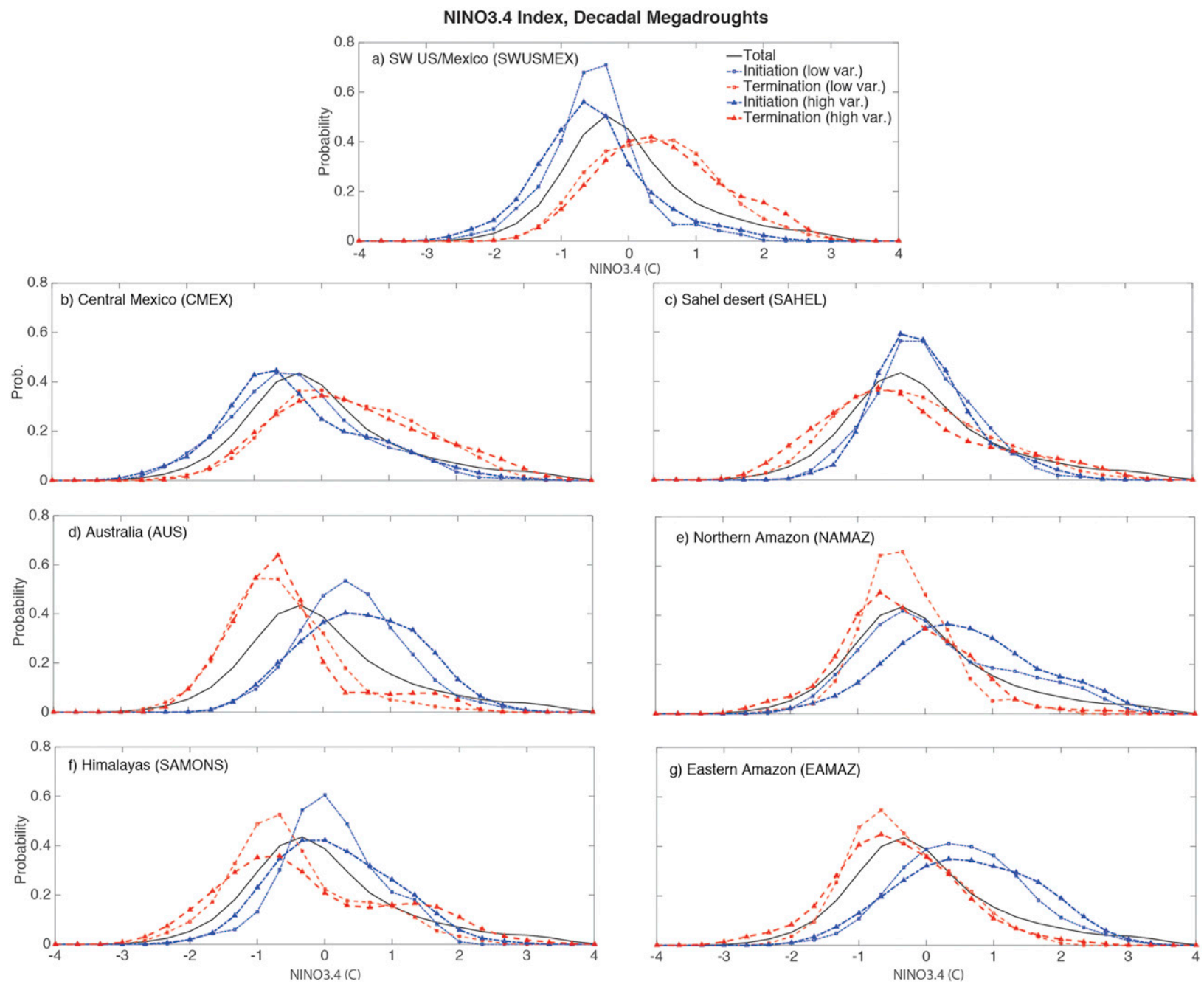

FIG. 6. (a)-(g) PDFs of the Niño-3.4 index $\left({ }^{\circ} \mathrm{C}\right)$ during starting and ending years of megadroughts in study regions of interest. Black lines indicate the overall Niño-3.4 PDF for all LME simulations, blue lines are the Niño-3.4 value during the starting year of megadrought events, and red lines are the value during the ending year of megadrought. Low- and high-variance epochs are plotted separately.

Volcanically induced changes to megaevent persistence are generally smaller than the persistence changes due to ENSO and the AMO and in most locations do not pass the threshold for statistical significance. There are only a few locations that seem to exhibit a coherent and significant response to volcanism: for megadroughts, such locations are eastern Australia and a small portion of the eastern United States, where persistence shortens. Changes to megapluvials, in contrast, are strongest in the northern Amazon and central/southern Mexico; in all cases, the persistence of megapluvials increases due to volcanic forcing. We hypothesize that these shifts are due to volcanically induced cooling of the land surface, which favors wetter soil conditions via impacts on evapotranspiration. This is also borne out by the mean wetting in the majority of study regions, shown in $0-30-\mathrm{cm}$ soil moisture in Fig. 5h. Interestingly, the majority of our study regions do not exhibit much change in megaevent persistence due strictly to volcanic forcing; the patterns associated with volcanic impacts appear quite distinct from ENSO-AMO effects.

In addition to direct influences on climate, volcanic forcing may also alter the expression of megadroughts and megapluvials through (i) modifying the amplitude of climate modes or (ii) changing the structure of teleconnections associated with those modes. The PDFs in Fig. 8 provide insight into (i) by showing the distribution of Niño-3.4 and AMO index values in sets of LME simulations with and without volcanic forcing. Minimal differences are present in the Niño-3.4 values (Fig. 8a). However, the volcanic and nonvolcanic AMO PDFs do differ significantly, bearing strong resemblances to the 
AMO Index, Decadal Megadroughts
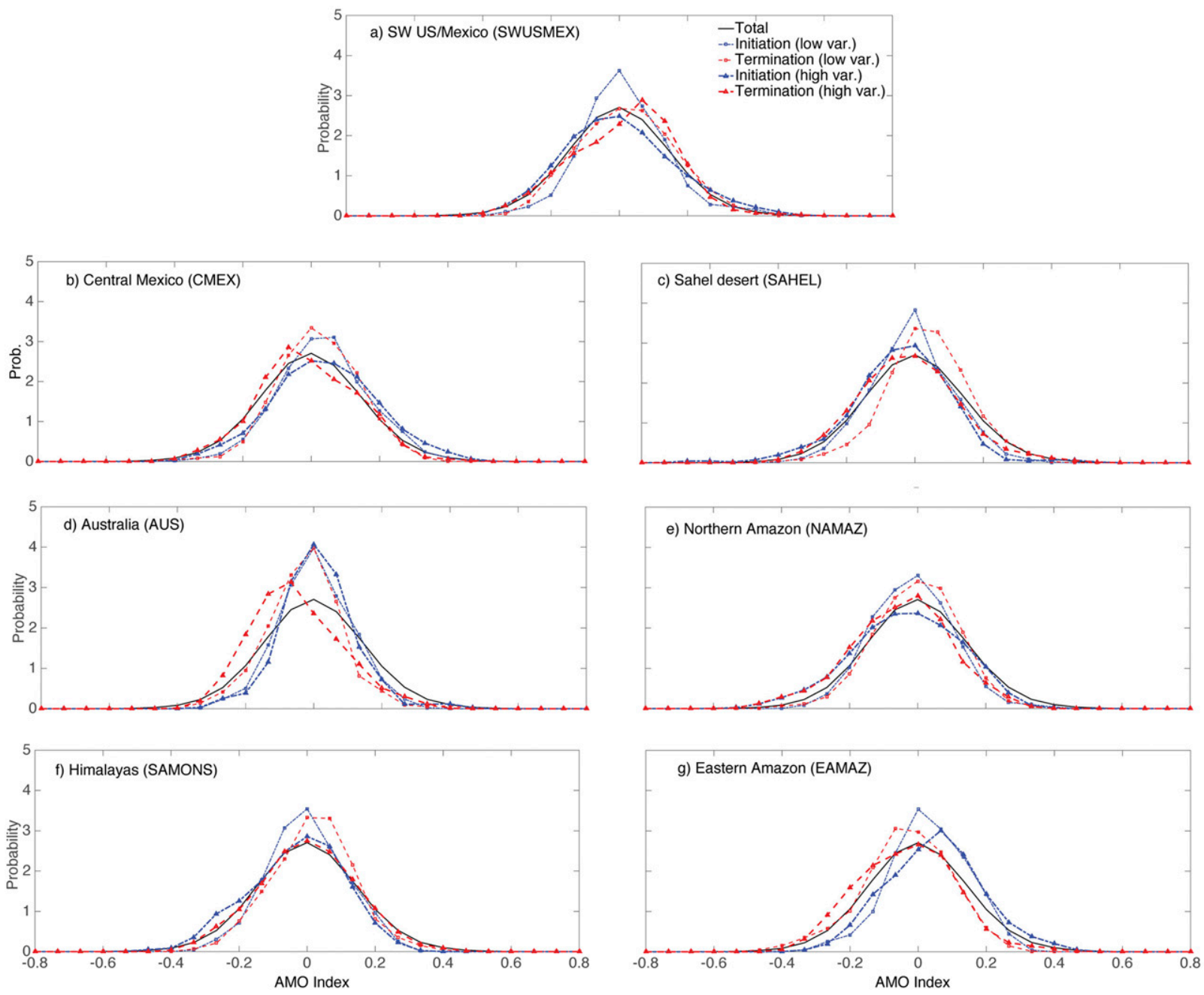

FIG. 7. As in Fig. 6, but for the AMO index.

high- and low-variance epochal PDFs, respectively. This is consistent with previous research on ENSO and AMO spectral behavior in the LME (Otto-Bliesner et al. 2016): volcanic forcing significantly enhances AMO strength but does not affect the long-term statistics of ENSO behavior. These results imply that the mean-state changes present in the AMO-stratified epochs of Fig. 5 may be reflecting the net impact of volcanic forcing, rather than strictly rectification of the AMO into the mean.

Figures 9 and 10 show the teleconnections with precipitation and temperature for volcanically stratified LME simulation sets for ENSO and the AMO, respectively. Volcanic forcing slightly enhances El Niñorelated warming and drying over Southeast Asia and cooling in the Himalayas (Figs. 9c,d). Some El Niño teleconnections weaken or even reverse due to volcanic impacts: cooling and wetting over the Amazon, drying in the western United States, wetting in Australia, and wetting over the Maritime Continent also oppose the canonical impacts of El Niño. However, the changes to teleconnections are relatively small, on the order of $5 \%-$ $10 \%$ in most locations.

To some extent, the changes to ENSO teleconnections due to volcanism are consistent with previously documented dynamical influences (Stevenson et al. 2016). For instance, volcanic aerosols are known to influence the ITCZ, the Southeast Asian monsoon, and the Northern Hemisphere subtropical jet in ways qualitatively resembling the El Niño teleconnection (Stevenson et al. 2016). This could explain the enhanced tendency toward warming and drying in some locations. However, this El Niño-like circulation shift is only significant in CESM for the first few years after the 

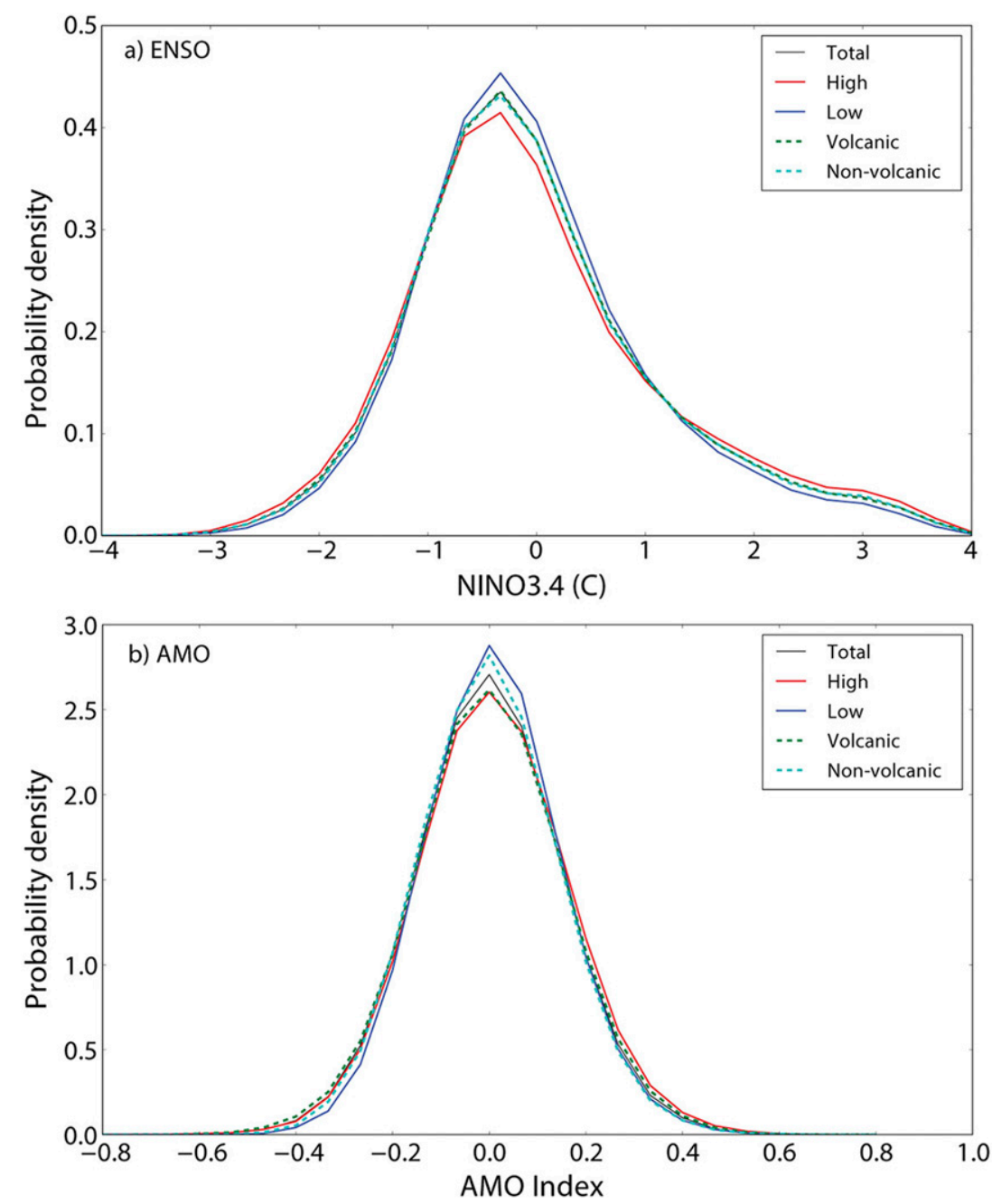

FIG. 8. PDFs of (a) Niño-3.4 and (b) AMO index values for overall LME, epochs of high vs low variance in the full set of LME simulations, and LME simulations with and without volcanic influences, respectively.

eruption, meaning that the net effect of aerosols on ENSO teleconnections is more complex. A sustained La Niña response is simulated 3-5 yr after major eruptions (Maher et al. 2015; Otto-Bliesner et al. 2016; Stevenson et al. 2016), and we hypothesize that some of these influences may be creating the tendency for weakened ENSO teleconnections in regions such as Australia and the western United States.

The changes to AMO teleconnections due to volcanic impacts are shown in Fig. 10. The warming over Northern Hemisphere landmasses during the positive phase of the AMO is enhanced by volcanism, with cooling occurring over Australia (Figs. 10a,c). The precipitation patterns in Figs. 10b and 10d are also consistent with these temperature changes. Volcanic influences enhance wetting just north of the equator and drying to the south, a pattern consistent with ITCZ migration into the warmer hemisphere (Kang et al. 2008). There may also be a contribution to the temperature and precipitation patterns by the Atlantic meridional overturning circulation (AMOC), which has been shown to strengthen following volcanic eruptions in the CESM and other climate models (Pausata et al. 2016; OttoBliesner et al. 2016). Partitioning the AMO- versus AMOC-driven portions of these shifts quantitatively, however, is beyond the scope of the present study.

The changes to megadrought risk associated with volcanically driven teleconnection shifts are assessed in Fig. 11. This is the same risk calculation performed in Fig. 4, but rather than examining the overall risk in simulations with and without volcanic aerosols, Fig. 11 now shows the risk stratified by ENSO and AMO 
a) ENSO TS regression

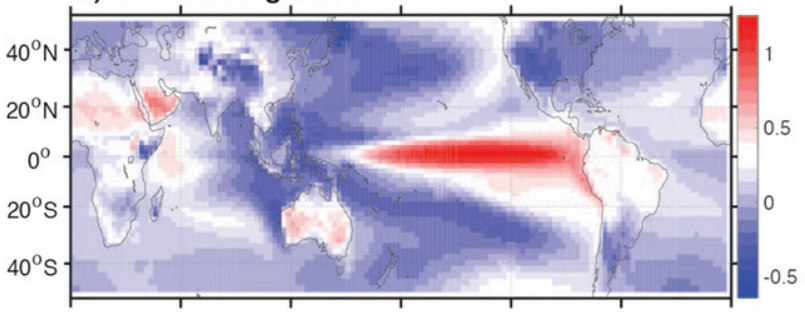

c) ENSO TS regression: volcanic - nonvolcanic

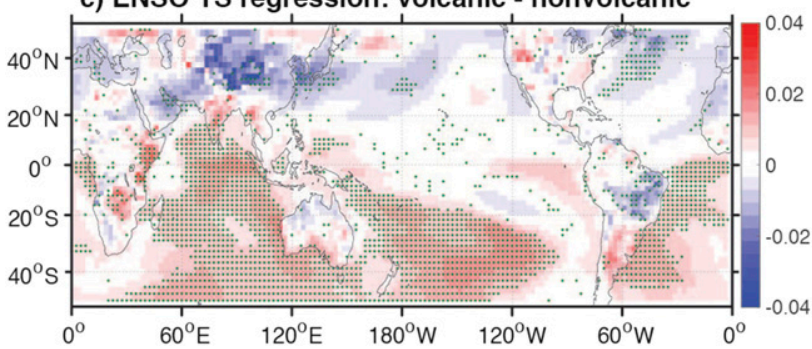

b) ENSO precip regression

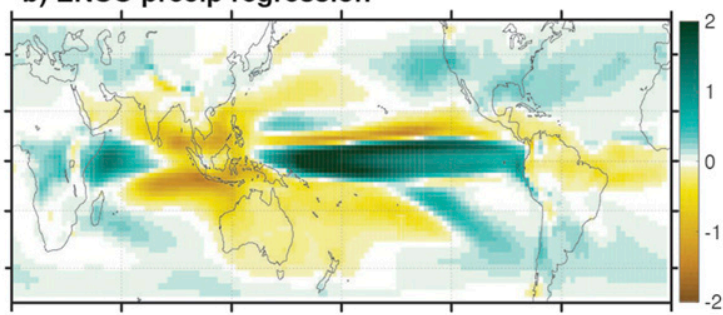

d) ENSO precip regression: volcanic - nonvolcanic

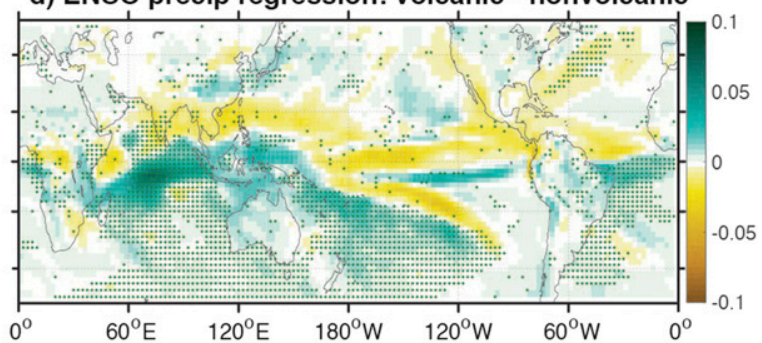

FIG. 9. Teleconnections with ENSO in LME simulations for (a) surface air temperature $\left[{ }^{\circ} \mathrm{C}\left({ }^{\circ} \mathrm{C}\right)^{-1}\right]$ and (b) precipitation $\left[\mathrm{mm}\right.$ day ${ }^{-1}$ $\left.\left({ }^{\circ} \mathrm{C}\right)^{-1}\right]$. (c),(d) As in (a),(b), but for LME simulations with and without the effects of volcanism. Stippling indicates regression differences significant at the $90 \%$ level, as measured using a Wilcoxon rank-sum test.

amplitude, in simulations with and without volcanic effects. ENSO-driven megadrought risk increases in CMEX and decreases in EAMAZ when volcanic effects are included, consistent with the El Niño-like effects discussed above. In SWUSMEX, much of Southeast Asia, including the SAMONS region, and all of Australia, ENSO-driven megadrought risk decreases due to volcanic forcing, consistent with our hypothesized $\mathrm{La}$ Niña-like influence on the teleconnection pattern in Fig. 9.

\section{a) AMO TS regression}

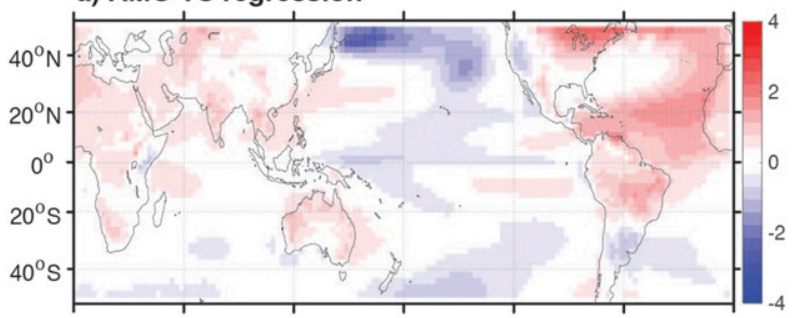

c) AMO TS regression: volcanic - nonvolcanic

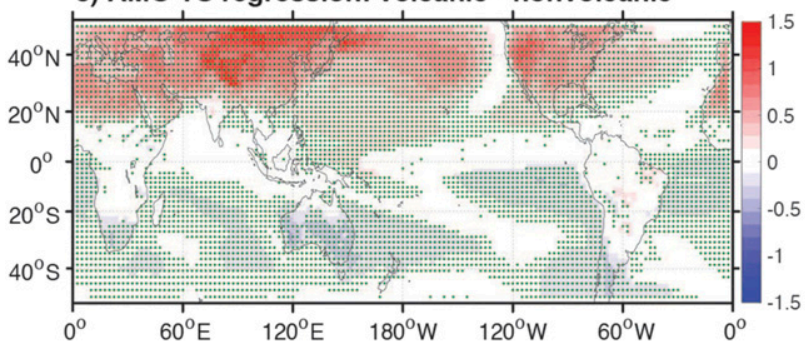

The relationship between forced AMO teleconnection changes and shifts in forced AMO-driven megadrought risk appears to be less straightforward than for ENSO. In several locations, there are suggestions that enhancements in AMO-driven temperature anomalies may play a dominant role: for example, in much of the southwestern United States and Southeast Asia, a marked tendency for the AMO to enhance megadrought risk due to volcanism (Fig. 11a vs 11c) seems to be driven primarily by more efficient AMO-driven

\section{b) AMO precip regression}

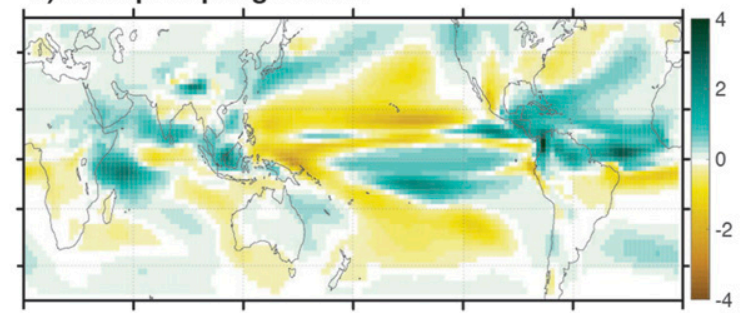

d) AMO precip regression: volcanic - nonvolcanic

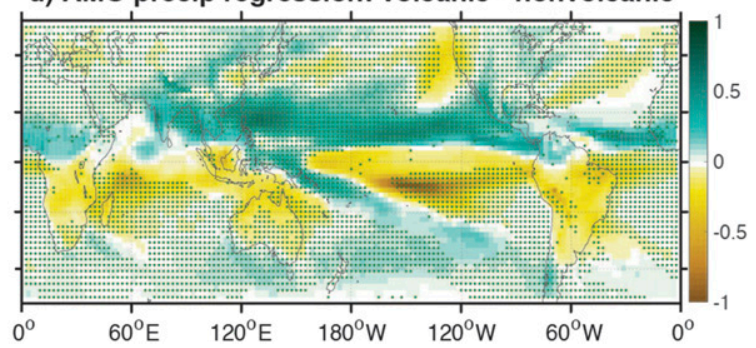

FIG. 10. As in Fig. 9, but for the AMO. 

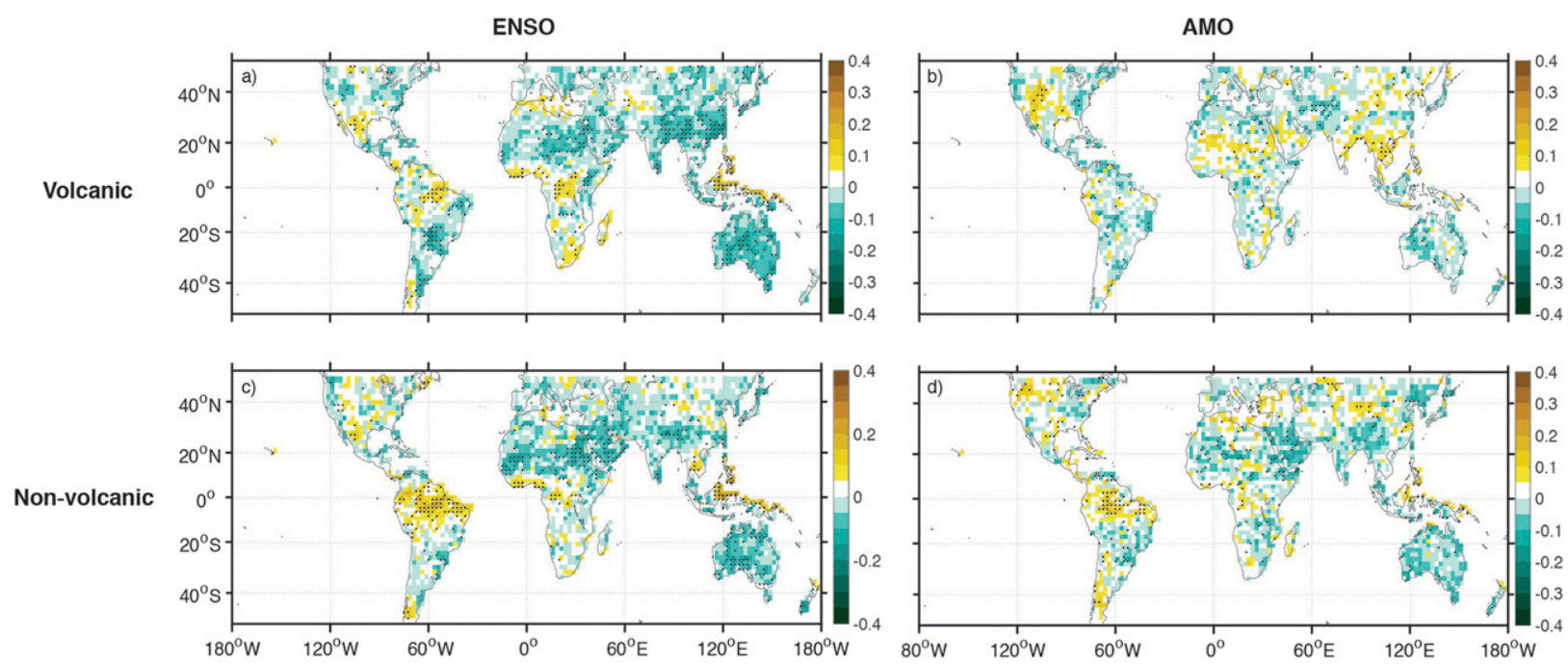

FIG. 11. Effects of (left) ENSO and (right) the AMO on megadrought risk in simulations: (top) with and (bottom) without the effects of volcanism. Stippling indicates differences insignificant at the $90 \%$ level, as measured using a Wilcoxon rank-sum test.

warming (Fig. 10c). In other locations, such as the northern Amazon, the reduction in risk associated with the AMO in the volcanic simulations seems driven by enhanced AMO-related positive rainfall anomalies (Fig. 10d vs 10b). Finally, in places such as the eastern Amazon and Australia, the underlying processes by which volcanism alters AMO-driven risk are somewhat unclear. For instance, the AMO-driven megadrought risk in the eastern Amazon is weaker in volcanic simulations, yet volcanic forcing also enhances AMOdriven drying in the region while having little impact on temperature. Australia also experiences volcanically driven drying: we hypothesize that these somewhat counterintuitive relationships may be caused by the stronger tendency for negative AMO excursions to create megadrought termination in these regions (Figs. 7c,f).

\section{Discussion and conclusions}

This study leverages the unique capabilities of the CESM Last Millennium Ensemble to explore statistical associations between worldwide megadrought persistence and risk, major modes of internal climate variability (i.e., ENSO and the AMO), and volcanic forcing. These influences are not able to explain the entirety of modulations in megadrought behavior, which we attribute to processes not included in coherent modes such as ENSO and the AMO; these effects may relate to internal atmospheric variability, land surface feedbacks, or other mechanisms. This result is consistent with previous studies showing significant stochastic (i.e., highfrequency atmospheric noise) influences on megadrought
(Stevenson et al. 2015; Coats et al. 2013, 2015b), and the details are left for future investigation. However, both ENSO and the AMO are found to significantly alter the persistence of both extreme megadrought and megapluvial periods. An increase in ENSO variance tends to reduce the persistence of megadrought in Australia, the Himalayas, the Sahel, and the southwestern United States. Corresponding increases in megapluvial persistences occur in these regions, with the net effect of reducing the overall risk of megadrought. The reduction in risk is significant, up to nearly $30 \%$ in some locations; this implies that the representation of ENSO variability is crucial to correctly representing simulated risks of megadrought in many drought-prone regions (Parsons et al. 2017). It should also be noted that increased ENSO variance does not always reduce megadrought risk: for example, in Mexico and much of the Amazon, megadrought persistence increases and megapluvial persistence decreases with increased ENSO variance, leading to an increase in megadrought risk. The regional structure of these ENSO-risk relationships is intriguing, and future work is recommended to understand how this relates to quantities such as ENSO skewness, biases in El Niño-La Niña teleconnections, or other processes.

The amplitude of the AMO does not affect megaevents as clearly as ENSO, but changes are nonetheless significant in many locations. The AMO influences are strongest for megadrought, particularly in the southwestern United States and the northern Amazon, where climatological AMO teleconnections are strongest. High AMO variance tends to enhance the persistence of southwestern United States megadrought and reduce the persistence of megadrought in the northern Amazon. In 


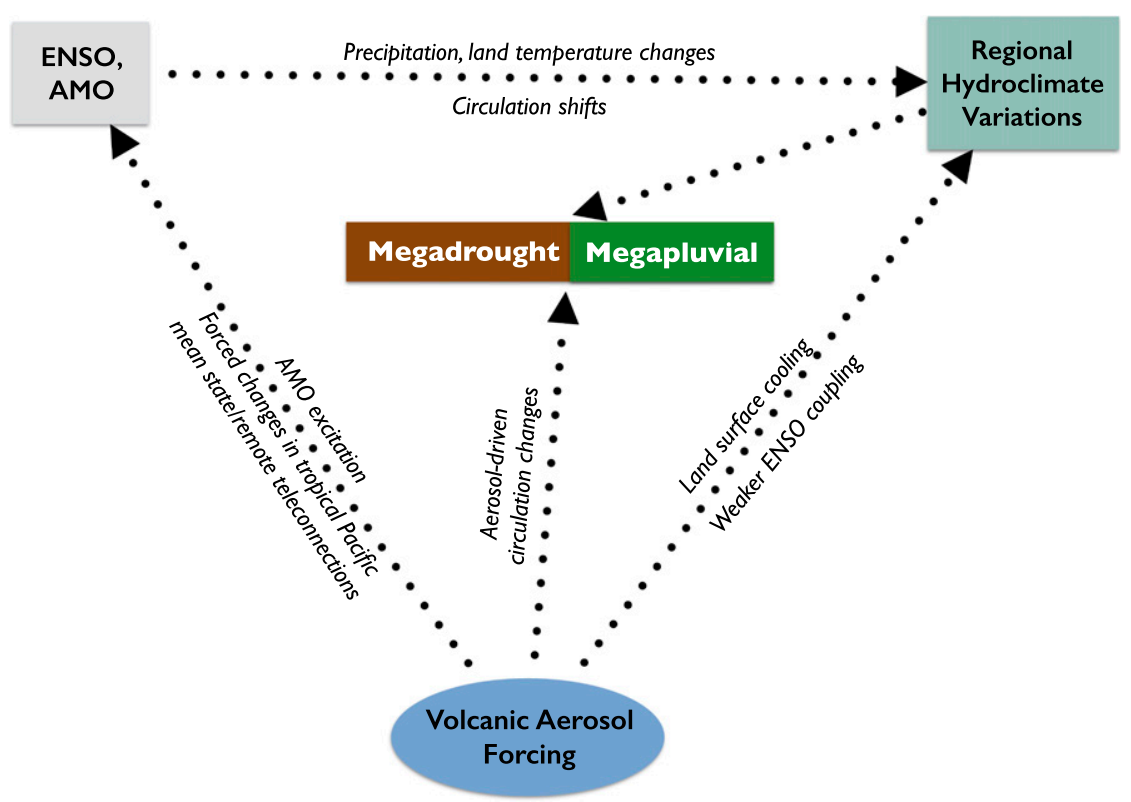

FIG. 12. Schematic illustrating the interaction among atmosphere-ocean modes of variability, volcanic forcing, and megaevents.

the latter region, an increase in megapluvial persistences is also detectable. Notably, changes in the Sahel are not significant, despite the generally strong AMO teleconnection in the region (Shanahan et al. 2009), which may reflect an issue with simulated AMO teleconnections in the CESM (Coats et al. 2016a,b).

Some of the ENSO- and AMO-driven changes to megadrought risk likely operate via "rectification" of modal teleconnections, where nonlinearities between teleconnected influences affect the long-term mean climate. For example, the teleconnections generated during positive and negative ENSO and AMO states have different signatures, and as such, the net effect of ENSO and AMO during epochs of high versus low variance will average to different states; in CESM, ENSO variability tends to favor cooling and wetting in the Himalayas, the southwestern United States, the Sahel, and Australia, which likely allows wet soil moisture conditions to persist longer in these locations and creates the above changes in megadrought and megapluvial persistences. Likewise, in the Amazon and Mexico, warmer and drier conditions exist overall when ENSO is stronger. This is consistent with a shift toward more El Niño-like conditions during high ENSO variance epochs as a result of enhanced occurrence of extreme El Niño events. In contrast, increases in AMO variability are associated with cooling globally, but this is likely reflecting the influence of volcanic forcing on the AMO.

Changes to megadrought risk in some locations also appear related to enhanced "switching" between phases of ENSO. For instance, there is a clear separation between El Niño and La Niña conditions during the starting versus ending years of megadrought events. La Niña events are systematically associated with megadrought initiation in the southwestern United States and with their termination in the Sahel, Australia, the Himalayas, and the Amazon; the reverse is true for $\mathrm{El}$ Niño. Higher ENSO-variance epochs appear primarily to shift Niño-3.4 PDFs toward stronger El Niño conditions, consistent with known asymmetries between El Niño and La Niña. The separation between AMO index values during megadrought initiation/termination years is not distinct for most regions, potentially as a result of the lower frequency of AMO variability.

Although not a topic of the present study, it is also possible that aspects of ENSO behavior other than variance may have a relationship with megadrought properties/risk. For instance, the skewness of the ENSO system is often not well captured by climate models (Guilyardi et al. 2009; Bellenger et al. 2014), meaning that differential impacts of El Niño versus La Niña on megadrought may not be skillfully represented. Since megadrought and megapluvial events in many regions are dependent on precipitation in certain seasons (i.e., winter storms in the Sierra Nevadas), the seasonal phase locking of ENSO might also play some role in affecting the ENSO-megadrought connection. Finally, the simulation of extreme El Niño and La Niña events is also of key interest for these purposes: these events are often associated with strong precipitation events in our study 
regions, and the frequency of such extremes is robustly projected to increase in climate models (Cai et al. 2014, 2015). These effects may be important for studies of twenty-first-century megadrought behavior.

The design of the LME allows the impact of individual external forcings to be explored; when risks of megadrought are compared across simulation sets with and without the effects of volcanic eruptions, we find that directly forced changes are relatively small. This may be due to the relatively short time scale of volcanic climate perturbations, which differing choices of running-mean computation for PDSI might illustrate. However, external forcings do significantly alter the impact of both ENSO and the AMO on megadrought risk: when volcanic simulations are included, the risk reduction due to high ENSO variance in the southwestern United States, the Himalayas, and Australia is stronger, the risk increase in Mexico is stronger, and the increase in the Amazon is weaker. Volcanically driven AMO risks are reduced in the Amazon and increased in the southwestern United States, and they likely also reflect the overall increase in AMO amplitude due to volcanic activity simulated in CESM. We note that although other forcings are smaller than volcanic eruptions, there may nonetheless be some possibility for forced changes in megadrought due to other mechanisms: solar forcing is a prime candidate for further investigation, as its decadal time scales may lend themselves to "resonant" behavior with megadrought. We recommend future dedicated studies to understand these mechanisms as well.

This work has important implications for the interpretation of paleoclimate reconstructions of megadrought, as well as the evaluation of model performance. Volcanic forcing affects the risk of megadrought, but the primary mechanism is the forced influence on atmosphereocean teleconnections, rather than the direct forcing of climate (see schematic in Fig. 12). As such, a complete assessment of volcanic impacts on megadrought requires both capturing volcanically forced changes to modes of coupled variability and representing the associated shifts in atmospheric teleconnections. Recent work [e.g., Colose et al. 2016; Stevenson et al. 2016; see review by Smerdon et al. (2017)] has highlighted the degree to which such forced changes depend on the properties of the input volcanic aerosol forcing, which is poorly constrained for many eruptions. Our work thus indicates the key role future improvements of estimated volcanic forcing may play in model evaluation efforts, as well as attribution of mechanisms for particular past megadrought events.

Acknowledgments. This work is supported by NSF EaSM Grants AGS-1243125 and NCAR-1243107 to The
University of Arizona. The CESM project is supported by the National Science Foundation and the Office of Science (Biological and Environmental Research program) of the U.S. Department of Energy. Computing resources were provided by the Climate Simulation Laboratory at NCAR's Computational and Information Systems Laboratory (CISL) sponsored by the National Science Foundation and other agencies.

\section{REFERENCES}

Acuna-Soto, R., D. W. Stahle, M. K. Cleaveland, and M. D. Therrell, 2002: Megadrought and megadeath in 16th century Mexico. Emerg. Infect. Dis., 8, 360-362, https://doi.org/10.3201\% 2Feid0804.010175.

Alley, W. M., 1984: The Palmer drought severity index: Limitations and assumptions. J. Climate Appl. Meteor., 23, 1100-1109, https:// doi.org/10.1175/1520-0450(1984)023<1100:TPDSIL > 2.0.CO;2.

Anchukaitis, K. J., B. M. Buckley, E. R. Cook, B. I. Cook, R. D. D'Arrigo, and C. M. Ammann, 2010: Influence of volcanic eruptions on the climate of the Asian monsoon region. Geophys. Res. Lett., 37, L22703, https://doi.org/10.1029/ 2010 GL044843.

Ault, T. R., J. E. Cole, J. T. Overpeck, G. T. Pederson, S. St. George, B. Otto-Bliesner, C. A. Woodhouse, and C. Deser, 2013: The continuum of hydroclimate variability in western North American during the last millennium. J. Climate, 26, 5863-5878, https://doi.org/10.1175/JCLI-D-11-00732.1.

_ _ J. S. Mankin, B. I. Cook, and J. E. Smerdon, 2016: Relative impacts of mitigation, temperature, and precipitation on 21stcentury megadrought risk in the American Southwest. Sci. $A d v ., 2$, e1600873, https://doi.org/10.1126/sciadv.1600873.

Bellenger, H., E. Guilyardi, J. Leloup, M. Lengaigne, and J. Vialard, 2014: ENSO representation in climate models: From CMIP3 to CMIP5. Climate Dyn., 42, 1999-2018, https:// doi.org/10.1007/s00382-013-1783-z.

Cai, W., and Coauthors, 2014: Increasing frequency of extreme El Niño events due to greenhouse warming. Nat. Climate Change, 4, 111-116, https://doi.org/10.1038/nclimate2100.

_ , and Coauthors, 2015: Increasing frequency of extreme La Niña events under greenhouse warming. Nat. Climate Change, 5, 132-137, https://doi.org/10.1038/nclimate2492.

Cayan, D. R., K. T. Redmond, and L. G. Riddle, 1999: ENSO and hydrologic extremes in the western United States. J. Climate, 12, 2881-2893, https://doi.org/10.1175/1520-0442(1999)012<2881: EAHEIT $>2.0 . \mathrm{CO} ; 2$.

—, T. Das, D. W. Pierce, T. Barnett, M. Tyree, and A. Gershunov, 2010: Future dryness in the southwest US and the hydrology of the early 21 st century drought. Proc. Natl. Acad. Sci. USA, 107, 21 271-21276, https://doi.org/10.1073/ pnas.0912391107.

Coats, S., and J. Mankin, 2016: The challenge of accurately quantifying future megadrought risk in the American Southwest. Geophys. Res. Lett., 43, 9225-9233, https://doi.org/10.1002/ 2016 GL070445.

—, J. E. Smerdon, R. Seager, B. I. Cook, and J. F. GonzálezRouco, 2013: Megadroughts in southwestern North America in ECHO-G millennial simulations and their comparison to proxy drought reconstructions. J. Climate, 26, 7635-7649, https://doi.org/10.1175/JCLI-D-12-00603.1. 
— B. I. Cook, J. E. Smerdon, and R. Seager, 2015a: North American pancontinental droughts in model simulations of the last millennium. J. Climate, 28, 2025-2043, https://doi.org/ 10.1175/JCLI-D-14-00634.1.

_- , J. E. Smerdon, B. I. Cook, and R. Seager, 2015b: Are simulated megadroughts in the North American Southwest forced? J. Climate, 28, 124-142, https://doi.org/10.1175/ JCLI-D-14-00071.1.

,,,---- E. R. Cook, and K. J. Anchukaitis, 2016a: Internal ocean-atmosphere variability drives megadroughts in western North America. Geophys. Res. Lett., 43, 9886-9894, https://doi.org/10.1002/2016GL070105.

,,-- K. B. Karnauskas, and R. Seager, 2016b: The improbable but unexceptional occurrence of megadrought clustering in the American West during the Medieval Climate Anomaly. Environ. Res. Lett., 11, 074025, https://doi.org/10.1088/ 1748-9326/11/7/074025.

Cole, J., and E. Cook, 1998: The changing relationship between ENSO variability and moisture balance in the continental United States. Geophys. Res. Lett., 25, 4529-4532, https:// doi.org/10.1029/1998GL900145.

—_, J. Overpeck, and E. Cook, 2002: Multiyear La Niña events and persistent drought in the contiguous United States. Geophys. Res. Lett., 29, 1647, https://doi.org/ 10.1029/2001GL013561.

Colose, C. M., A. N. LeGrande, and M. Vuille, 2016: Hemispherically asymmetric volcanic forcing of tropical hydroclimate during the last millennium. Earth Syst. Dyn., 7, 681-696, http://www.earth-syst-dynam.net/7/681/2016/.

Conroy, J. L., J. T. Overpeck, J. Cole, and M. Steinitz-Kannan, 2009a: Variable oceanic influences on western North American drought over the last 1200 years. Geophys. Res. Lett., 36, L17703, https://doi.org/10.1029/2009GL039558.

— A. Restrepo, J. T. Overpeck, M. Steinitz-Kannan, J. E. Cole, M. B. Bush, and P. A. Colinvaux, 2009b: Unprecedented recent warming of surface temperatures in the eastern tropical Pacific Ocean. Nat. Geosci., 2, 46-50, https://doi.org/10.1038/ ngeo390.

Cook, B. I., T. R. Ault, and J. E. Smerdon, 2015: Unprecedented 21st century drought risk in the American Southwest and central Plains. Sci. Adv., 1, e1400082, https://doi.org/10.1126/ sciadv.1400082.

—, E. R. Cook, J. E. Smerdon, R. Seager, A. P. Williams, S. Coats, D. W. Stahle, and J. Villanueva Diaz, 2016: North American megadroughts in the Common Era: Reconstructions and simulations. Wiley Interdiscip. Rev.: Climate Change, 7, 411-432, https://doi.org/10.1002/wcc.394.

Cook, E., C. Woodhouse, C. Eakin, D. Meko, and D. Stahle, 2004: Long-term aridity changes in the western United States. Science, 306, 1015-1018, https://doi.org/10.1126/science.1102586.

— , K. Anchukaitis, B. Buckley, R. D'Arrigo, G. Jacoby, and W. Wright, 2010: Asian monsoon failure and megadrought during the last millennium. Science, 328, 486-489, https:// doi.org/10.1126/science.1185188.

Dai, A., K. E. Trenberth, and T. Qian, 2004: A global data set of Palmer drought severity index for 1870-2002: Relationship with soil moisture and effects of surface warming. J. Hydrometeor., 5, 1117-1130, https://doi.org/10.1175/ JHM-386.1.

Deser, C., A. S. Phillips, and M. A. Alexander, 2010: Twentieth century tropical sea surface temperature trends revisited. Geophys. Res. Lett., 37, L10701, https://doi.org/10.1029/ 2010GL043321.
Fasullo, J. T., and R. S. Nerem, 2016: Interannual variability in global mean sea level estimated from the CESM Large and Last Millennium Ensembles. Water, 8, 491, https://doi.org/ 10.3390/w8110491.

, D. Lawrence, and S. Swenson, 2016: Are GRACE-era terrestrial water trends driven by anthropogenic climate change? Adv. Meteor., 2016, 4830603, https://doi.org/10.1155/2016/ 4830603.

Feng, S., R. Oglesby, C. Rowe, D. Loope, and Q. Hu, 2008: Atlantic and Pacific SST influences on medieval drought in North America simulated by the Community Atmospheric Model. J. Geophys. Res., 113, D11101, https://doi.org/10.1029/ 2007JD009347.

Gautier, D., D. Denis, and B. Locatelli, 2016: Impacts of drought and responses of rural populations in West Africa: A systematic review. Wiley Interdiscip. Rev.: Climate Change, 7, 666-681, https://doi.org/10.1002/wcc.411.

Gleckler, P., K. Taylor, and C. Doutriaux, 2008: Performance metrics for climate models. J. Geophys. Res., 113, D06104, https://doi.org/10.1029/2007JD008972.

Graham, N. E., T. Barnett, R. Wilde, M. Ponater, and S. Schubert, 1994: On the roles of tropical and midlatitude SSTs in forcing interannual to interdecadal variability in the winter Northern Hemisphere circulation. J. Climate, 7, 1416-1441, https://doi.org/10.1175/1520-0442(1994)007<1416: OTROTA $>2.0 . \mathrm{CO} ; 2$.

—, and Coauthors, 2007: Tropical Pacific-mid-latitude teleconnections in medieval times. Climatic Change, 83, 241-285, https://doi.org/10.1007/s10584-007-9239-2.

C. M. Ammann, D. Fleitmann, K. M. Cobb, and J. Luterbacher, 2011: Support for global climate reorganization during the "Medieval Climate Anomaly." Climate Dyn., 37, 1217-1245, https://doi.org/10.1007/s00382-010-0914-z.

Griffin, D., and K. J. Anchukaitis, 2014: How unusual is the 20122014 California drought? Geophys. Res. Lett., 41, 9017-9023, https://doi.org/10.1002/2014GL062433.

Guilyardi, E., A. Wittenberg, A. Fedorov, M. Collins, C. Wang, A. Capotondi, G. J. van Oldenborgh, and T. Stockdale, 2009: Understanding El Niño in ocean-atmosphere general circulation models: Progress and challenges. Bull. Amer. Meteor. Soc., 90, 325-340, https://doi.org/10.1175/ 2008BAMS2387.1.

Held, I., T. Delworth, J. Lu, K. Findell, and T. Knutson, 2005: Simulation of Sahel drought in the 20th and 21st centuries. Proc. Natl. Acad. Sci. USA, 102, 17 891-17 896, https://doi.org/ 10.1073/pnas.0509057102.

Herweijer, C., R. Seager, E. R. Cook, and J. Emile-Geay, 2007: North American droughts of the last millennium from a gridded network of tree-ring data. J. Climate, 20, 1353-1376, https://doi.org/10.1175/JCLI4042.1.

Huang, B., and Coauthors, 2015: Extended Reconstructed Sea Surface Temperature version 4 (ERSST.v4). Part I: Upgrades and intercomparisons. J. Climate, 28, 911-930, https://doi.org/ 10.1175/JCLI-D-14-00006.1.

Jacobi, J., D. Perrone, L. L. Duncan, and G. Hornberger, 2013: A tool for calculating the Palmer drought indices. Water Resour. Res., 49, 6086-6089, https://doi.org/10.1002/wrcr.20342.

Kang, S. M., I. M. Held, D. M. W. Frierson, and M. Zhao, 2008: The response of the ITCZ to extratropical thermal forcing: Idealized slab-ocean experiments with a GCM. J. Climate, 21, 35213532, https://doi.org/10.1175/2007JCLI2146.1.

Kushnir, Y., R. Seager, M. Ting, N. Naik, and J. Nakamura, 2010: Mechanisms of tropical Atlantic SST influence on North 
American precipitation variability. J. Climate, 23, 5610-5628, https://doi.org/10.1175/2010JCLI3172.1.

Li, J., and Coauthors, 2013: El Niño modulations over the past seven centuries. Nat. Climate Change, 3, 822-826, https:// doi.org/10.1038/nclimate1936.

Maher, N., S. McGregor, M. H. England, and A. Sen Gupta, 2015: Effects of volcanism on tropical variability. Geophys. Res. Lett., 42, 6024-6033, https://doi.org/10.1002/ 2015 GL064751.

McAfee, S. A., 2014: Consistency and the lack thereof in Pacific decadal oscillation impacts on North American winter climate. J. Climate, 27, 7410-7431, https://doi.org/10.1175/ JCLI-D-14-00143.1.

McCabe, G. J., M. A. Palecki, and J. L. Betancourt, 2004: Pacific and Atlantic Ocean influences on multidecadal drought frequency in the United States. Proc. Natl. Acad. Sci. USA, 101, 4136-4141, https://doi.org/10.1073/ pnas.0306738101.

Newman, M., and Coauthors, 2016: The Pacific decadal oscillation, revisited. J. Climate, 29, 4399-4427, https://doi.org/10.1175/ JCLI-D-15-0508.1.

Oglesby, R., S. Feng, Q. Hu, and C. Rowe, 2012: The role of the Atlantic multidecadal oscillation on medieval drought in North America: Synthesizing results from proxy data and climate models. Global Planet. Change, 84-85, 56-65, https:// doi.org/10.1016/j.gloplacha.2011.07.005.

Otto-Bliesner, B., and Coauthors, 2016: Climate variability and change since $850 \mathrm{CE}$ : An ensemble approach with the Community Earth System Model (CESM). Bull. Amer. Meteor. Soc., 97, 735-754, https://doi.org/10.1175/ BAMS-D-14-00233.1.

Palmer, J. G., and Coauthors, 2015: Drought variability in the eastern Australia and New Zealand summer drought atlas (ANZDA, CE 1500-2012) modulated by the interdecadal Pacific oscillation. Environ. Res. Lett., 10, 124002, https:// doi.org/10.1088/1748-9326/10/12/124002.

Palmer, W. C., 1965: Meteorological drought. U.S. Department of Commerce Research Paper 45, 65 pp., https:// www.ncdc.noaa.gov/temp-and-precip/drought/docs/palmer.pdf.

Parsons, L. A., G. R. Loope, J. T. Overpeck, T. R. Ault, R. Stouffer, and J. E. Cole, 2017: Temperature and precipitation variance in CMIP5 simulations and paleoclimate records of the last millennium. J. Climate, 30, 8885-8912, https://doi.org/10.1175/ JCLI-D-16-0863.1.

Pausata, F. S. R., C. Karamperidou, R. Caballero, and D. S. Battisti, 2016: ENSO response to high-latitude volcanic eruptions in the Northern Hemisphere: The role of the initial conditions. Geophys. Res. Lett., 43, 8694-8702, https://doi.org/10.1002/ 2016GL069575.

Phillips, A. S., C. Deser, and J. Fasullo, 2014: Evaluating modes of variability in climate models. Eos, Trans. Amer. Geophys. Union, 95, 453-455, https://doi.org/10.1002/ 2014EO490002.

Power, S., M. Haylock, R. Colman, and X. Wang, 2006: The predictability of interdecadal changes in ENSO activity and ENSO teleconnections. J. Climate, 19, 4755-4771, https:// doi.org/10.1175/JCLI3868.1.

Rayner, N. A., D. E. Parker, E. B. Horton, C. K. Folland, L. V. Alexander, D. P. Rowell, E. C. Kent, and A. Kaplan, 2003: Global analyses of sea surface temperature, sea ice, and night marine air temperature since the late nineteenth century. J. Geophys. Res., 108, 4407, https://doi.org/10.1029/ 2002JD002670.
Routson, C. C., C. A. Woodhouse, J. T. Overpeck, J. L. Betancourt, and N. P. McKay, 2016: Teleconnected ocean forcing of western North American droughts and pluvials during the last millennium. Quat. Sci. Rev., 146, 238-250, https://doi.org/ 10.1016/j.quascirev.2016.06.017.

Schmidt, G. A., and Coauthors, 2011: Climate forcing reconstructions for use in PMIP simulations of the last millennium (v1.0). Geosci. Model Dev., 4, 33-45, https://doi.org/ 10.5194/gmd-4-33-2011.

Seager, R., 2015: Decadal hydroclimate variability across the Americas. Climate Change: Multidecadal and Beyond, C. Chang et al., Eds., World Scientific, 235-254.

- - , and M. Ting, 2017: Decadal drought variability over North America: Mechanisms and predictability. Curr. Climate Change Rep., 3, 141-149, https://doi.org/10.1007/ s40641-017-0062-1.

—_, R. Burgman, Y. Kushnir, A. Clement, E. Cook, N. Naik, and J. Miller, 2008: Tropical Pacific forcing of North American medieval megadroughts: Testing the concept with an atmosphere model forced by coral-reconstructed SSTs. J. Climate, 21, 6175-6190, https://doi.org/10.1175/ 2008JCLI2170.1.

_ M. Ming, C. Li, N. Naik, B. I. Cook, J. Nakamura, and H. Liu, 2013: Projections of declining surface-water availability for the southwestern United States. Nat. Climate Change, 3, 482-486, https://doi.org/10.1038/nclimate1787.

Shanahan, T., and Coauthors, 2009: Atlantic forcing of persistent drought in West Africa. Science, 324, 377-380, https://doi.org/ 10.1126/science. 1166352 .

Smerdon, J., and Coauthors, 2017: Comparing proxy and model estimates of hydroclimate variability and change over the Common Era. Climate Past, 13, 1851-1900, https://doi.org/ 10.5194/cp-13-1851-2017.

Stahle, D. W., and Coauthors, 2016: The Mexican Drought Atlas: Tree-ring reconstructions of the soil moisture balance during the late pre-Hispanic, colonial, and modern eras. Quat. Sci. Rev., 149, 34-60, https://doi.org/10.1016/ j.quascirev.2016.06.018.

Stevenson, S., A. Timmermann, Y. Chikamoto, S. Langford, and P. DiNezio, 2015: Stochastically generated North American megadroughts. J. Climate, 28, 1865-1880, https://doi.org/ 10.1175/JCLI-D-13-00689.1.

— B. B. Otto-Bliesner, J. Fasullo, and E. Brady, 2016: “El Niño like" hydroclimate responses to last millennium volcanic eruptions. J. Climate, 29, 2907-2921, https://doi.org/10.1175/ JCLI-D-15-0239.1.

—_, J. T. Fasullo, B. L. Otto-Bliesner, R. A. Tomas, and C. Gao, 2017: Role of eruption season in reconciling model and proxy responses to tropical volcanism. Proc. Natl. Acad. Sci. USA, 114, 1822-1826, https://doi.org/10.1073/ pnas. 1612505114 .

St. George, S., D. M. Meko, and E. R. Cook, 2010: The seasonality of precipitation signals embedded within the North American Drought Atlas. Holocene, 20, 983-988, https://doi.org/10.1177/ 0959683610365937.

Stine, S., 1994: Extreme and persistent drought in California and Patagonia during mediaeval time. Nature, 369, 546-549, https://doi.org/10.1038/369546a0.

Taschetto, A. S., A. S. Gupta, C. C. Ummenhofer, and M. H. England, 2016: Can Australian multiyear droughts and wet spells be generated in the absence of oceanic variability? J. Climate, 29, 6201-6221, https://doi.org/10.1175/ JCLI-D-15-0694.1. 
Ting, M., Y. Kushnir, R. Seager, and C. Li, 2011: Robust features of Atlantic multi-decadal variability and its climate impacts. Geophys. Res. Lett., 38, L17705, https://doi.org/10.1029/ 2011 GL048712.

Trenberth, K. E., and D. J. Shea, 2006: Atlantic hurricanes and natural variability in 2005. Geophys. Res. Lett., 33, L12704, https://doi.org/10.1029/2006GL026894.

Udall, B., and J. T. Overpeck, 2017: The twenty-first century Colorado River hot drought and implications for the future. Water Resour. Res., 53, 2404-2418, https://doi.org/10.1002/ 2016WR019638.

Ummenhofer, C. C., M. H. England, P. C. McIntosh, G. A Meyers, M. J. Pook, J. S. Risbey, A. Sen Gupta, and A. S. Taschetto, 2009: What causes southeast Australia's worst droughts? Geophys. Res. Lett., 36, L04706, https://doi.org/ 10.1029/2008GL036801.
Villamayor, J., and E. Mohino, 2015: Robust Sahel drought due to the interdecadal Pacific oscillation in CMIP5 simulations. Geophys. Res. Lett., 42, 1214-1222, https://doi.org/10.1002/ 2014GL062473.

Woodhouse, C. A., and J. T. Overpeck, 1998: 2000 years of drought variability in the central United States. Bull. Amer. Meteor. Soc., 79, 2693-2714, https://doi.org/10.1175/ 1520-0477(1998)079<2693:YODVIT>2.0.CO;2.

- G. T. Pederson, K. Morino, S. A. McAfee, and G. J. McCabe, 2016: Increasing influence of air temperature on upper Colorado River streamflow. Geophys. Res. Lett., 43, 2174-2181, https://doi.org/10.1002/2015GL067613.

Zeng, N., J.-Y. Yoon, J. A. Marengo, A. Subramaniam, C. A. Nobre, A. Mariotti, and J. D. Neelin, 2008: Causes and impacts of the 2005 Amazon drought. Environ. Res. Lett., 3, 014002, https://doi.org/10.1088/1748-9326/3/1/014002. 